\title{
MANUEL GODOY, GENIO DELLE SCAVAZIONI. ALGUNAS PRECISIONES ACERCA DE SUS DESCUBRIMIENTOS ARQUEOLÓGICOS EN EL MONTE CELIO DE ROMA
}

\author{
POR \\ JORGE GARCÍA SÁNCHEZ \\ Escuela Española de Historia y Arqueología en Roma (CSIC)
}

\section{RESUMEN}

A imitación de la aristocracia de la época napoleónica, Manuel Godoy llevó a cabo excavaciones arqueológicas en la villa que poseyó en Roma durante sus años de exilio, ubicada en el monte Celio. El arquitecto Antonio Celles, quien rehabilitaba el palacio y los jardines de la villa, dirigió varios de estos trabajos entre 1813 y 1815. Fruto de éstos, y de excavaciones posteriores, fue el descubrimiento del célebre herma de Sócrates y Séneca, única imagen fidedigna del filósofo hispano, hoy localizada en Berlín, y de dos basas de estatua dedicadas a Caracalla, gracias a las cuales se conoció dónde se situaba el cuartel de la Cohors V Vigilum de Roma.

\section{SUMMARY}

During his exile, the Spanish politician Manuel Godoy patronized archaeological excavations in his Roman villa, as the napoleonic aristocracy did. The architect Antonio Celles managed the works in the site throughout 1813 and 1815, while he was restoring Godoy's palace and garden. The famous Socrates and Seneca marble portrait, the only reliable image of the Spanish philosopher -at the present time in the Berlin Museum-, and two statue bases consecrated to Caracalla -key to place the quarters of Cohors V Vigilum of Rome-, were brought to light in these excavations.

PALABRAS CLAVE: Arqueología del siglo XIX. Monte Celio. Manuel Godoy. Antonio Celles. Lorenzo Re. Herma de Sócrates y Séneca. Cohors V Vigilum.

KEY WORDS: Archaeology 19th century. Celio hill. Manuel Godoy. Antonio Celles. Lorenzo Re. Socrates and Seneca marble portrait. Cohors V Vigilum.

El 18 de junio de 1812 entraban por la Porta del Popolo Carlos IV y María Luisa de Borbón y Parma, destronados por Napoleón y forzados a un exilio que se prolongaría en Roma hasta su fallecimiento, con unos pocos días de diferencia entre uno y otro, en 1819. El gran cortejo que acompañaba a los monarcas, como convenía a un rey destronado, contaba entre sus miembros al favorito de Carlos IV, su Primer Ministro y Capitán General del Ejército Nacional, Manuel Godoy, duque de la Alcudia y Sueca, o como sería mayormente conocido en su nueva ciudad de acogida ${ }^{1}$, Príncipe de la Paz y de Bassano $^{2}$. Godoy ya no tenía que preocuparse de la alta política ni de los asuntos internacionales, en la medida en que éstos no lo afectaran a él, y se dedicó plenamente a desarrollar sus aficiones artísticas y mundanas, tan presentes en la Italia francesa y posteriormente en la de la Restauración, cuya vida social cosmopolita buscaba olvidar la etapa anterior, como el resto de las naciones europeas. Así, a la manera de los ricos príncipes romanos y de la sociedad francesa surgida en Roma, coleccionó obras de arte y antigüedades, se convirtió en mecenas y protector de artistas, en su caso, sobre todo españoles, y participó asiduamente en todos los actos que la aristocracia local desarrollaba. Entre las diferentes propiedades que el Príncipe de la Paz poseyó distribuidas por la ciudad de Roma se encontraba la Villa Mattei -ahora rebautizada Celimontana- sobre el monte Celio, desde hacía tiempo en pésimas condiciones, que pretendía convertir en un auténtico museo de arte y un rincón de ocio (Fig. 1). Efectivamente, las guías de Roma de los primeros años del siglo XIX señalan la decadencia de la Villa Mattei: la de Vasi de 1804 apunta que era una de las más bellas de la ciudad por sus fuentes, bosques y por su colección de estatuas, bustos y mármoles antiguos, "non rimanendovi ora, che alcune statue, e busti

1 Godoy había residido junto a los monarcas exiliados en Fontainebleau, Compiègne, Marsella y Niza; tras la muerte de los reyes en 1819, permaneció todavía trece años en Roma, desde donde se trasladaría a París. Allí falleció en 1851. Alberto Fernández, "El inacabable destierro de Don Manuel Godoy, Príncipe de la Paz", Historia y vida, n. ${ }^{\circ} 43,1971$, pp. 90-101. Véase en relación a la estancia del ministro de Carlos IV en Roma Alessandro Bocca, "Godoy principe.... godereccio a Roma (1812-1832)", Strenna dei Romanisti, Roma, abril 1965, pp. 41-49.

2 El título de Príncipe de Bassano lo recibió con posterioridad, a finales de 1829, con la compra del feudo de dicho nombre perteneciente a la familia Giustiniani, lo que le significó la concesión de la ciudadanía romana por parte de Pío VIII. Cándido Pardo González, D. Manuel Godoy y Álvarez Faria Príncipe de la Paz, Madrid, 1911, p. 276. 


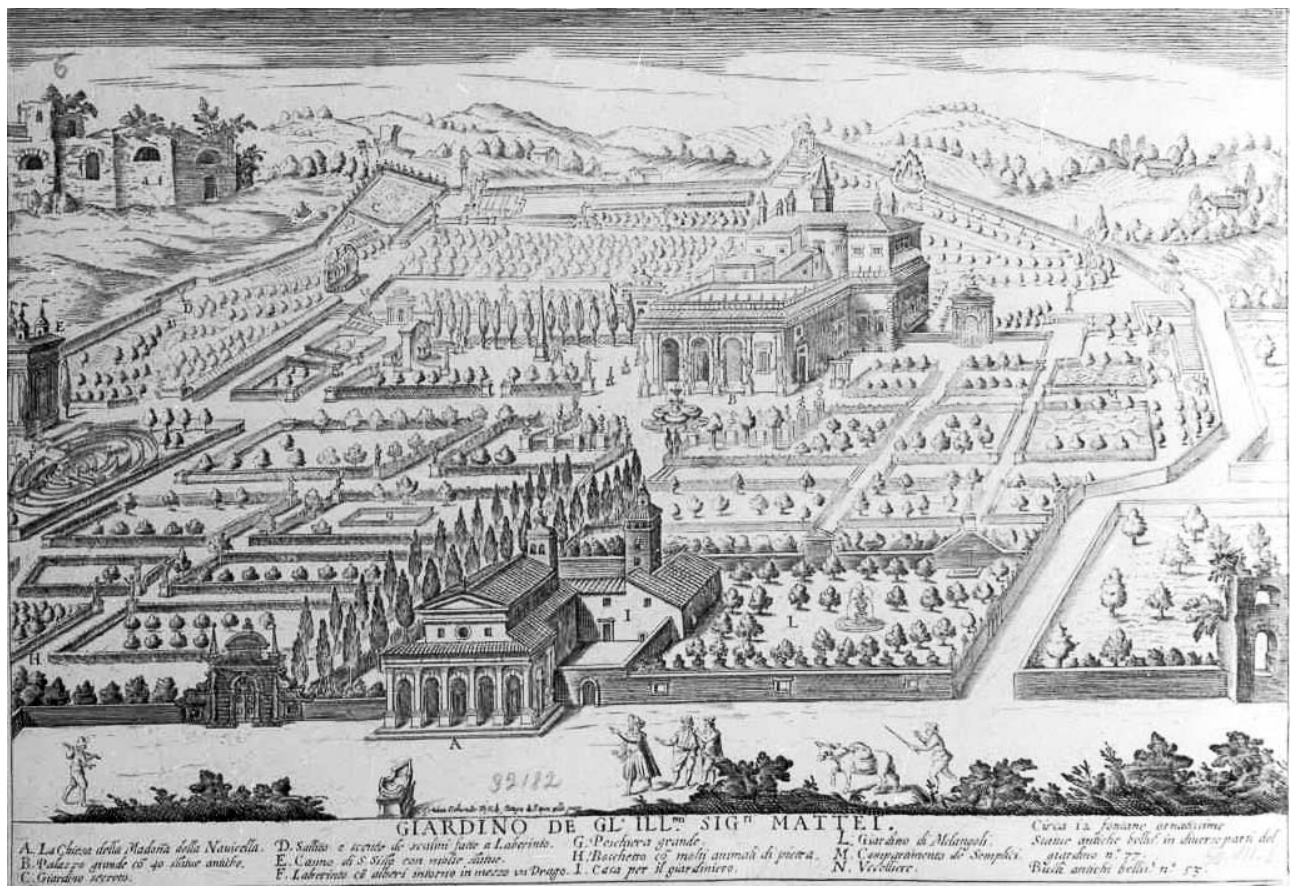

Figura 1. G. B. de Rossi. Veduta generale di Villa Mattei (con la Navicella en primer término). S. XVII. Roma. BIASA. R.XI.50.VII.6.

assi mediocri" ${ }^{3}$, mientras que los arquitectos franceses Percier y Fontaine, que grabaron tres vistas de la villa en 1809, describen el abandono de sus jardines ${ }^{4}$.

Para su recuperación el Príncipe de la Paz se dispuso a afrontar grandes obras de reforma, y el arquitecto designado para ello fue Antonio Celles, un joven catalán que la Junta de Comercio de Barcelona tenía pensionado en la Urbe para el estudio de su profesión y antiguo conocido de Godoy, a quien dedicó en Madrid los planos de un Colegio Militar ${ }^{5}$.

\footnotetext{
3 Mariano Vasi, Itinerario istruttivo di Roma antica e moderna, Roma, 1804, vol. I, p. 125. La guía de Prunetti observa con igual tono que Fu celebre già per una numerosa collezione di statue, busti, bassirilievi ed altri antichi marmi, di cui ora poco esiste. M. Prunetti, L'Osservatore delle Beller Arti in Roma ossia esame analitico de' monumenti antichi, e moderni spettanti alla Pittura, scultura, e Architettura, Roma, 1808, p. 149.

${ }^{4}$ C. Percier, P. F. L. Fontaine, Choix des plus célebres maisons de plaisance de Rome et de ses environs, missurées et dessinées par Percier et Fontaine, Roma, 1824 (2 ed.), p. 11.

5 El valido de Carlos IV fue Protector de la Real Academia de San Fernando durante los años 1792 y 1798, periodo en el que entró en contacto con él Antonio Celles, alumno de dicha institución desde 1790. En lo concerniente a las actividades arqueológicas desarrolladas en Roma por Antonio Celles, Joseph M. ${ }^{a}$ Montaner, "L'estada a Roma de l'arquitecte cátala Antoni Celles Azcona (1803-1815)", L'Avenc, n. ${ }^{\circ}$ 120, 1988,
}

Las operaciones arqueológicas llevadas a cabo en la Villa Celimontana siendo el Príncipe de la Paz su poseedor fueron seis, desarrolladas entre 1813 y 1815 y en 1820, y su resultado, el hallazgo de un caldarium, dos pavimentos, el célebre herma de Sócrates y Séneca de Berlín y dos basas inscritas. Gran parte de los descubrimientos realizados se dieron a consecuencia del programa de renovación que había emprendido Godoy en la villa con la ayuda de Antonio Celles, convertido de la mano de aquél en arqueólogo: no sólo el hallazgo del caldarium, sino también de los dos pavimentos y del herma fueron hechos casuales (ligados sobre todo al trazado de los caminos internos de los amplios jardines Mattei), que el nuevo propietario no dejó de aprovechar. Las demás intervenciones sí responden en cambio a una actividad intencionada muy relacionada con ese deseo de convertir en verdaderos museos de antigüedades clásicas e imprimir un aspecto arqueológico a las residencias aristocráticas durante el periodo napoleónico. Hasta

pp. 16-24; íd., La modernitzacióde l'utillatge mental de l'arquitectura a Catalunya (1714-1859), Barcelona, 1990; Juan Bassegoda Nonell, "Vida y obra del arquitecto Antonio Celles Azcona (1775-1835)", Academia, n. ${ }^{\circ} 88,1990$, pp. 19-30; A. M. Colini, "Storia e topografía nel Celio nell'Antichità", en Memorie della Pontificia Academia Romana di Archeologia, vol. VII, Roma, 1947, pp. 225-228. 
entonces la colección de obras antiguas de Godoy era meramente accidental, pues se componía tan sólo de las piezas de menor valor que habían permanecido en la villa tras la venta del resto por la familia Mattei, fundamentalmente al Museo Pío Clementino ${ }^{6}$; en cualquier caso, el interés de Godoy por la arqueología y sus aficiones anticuarias ya se manifestaron durante su etapa dorada en la Corte de Madrid, cuando patrocinó excavaciones y viajes artísticos, aspecto que ha sido resaltado por Alicia María Canto ${ }^{7}$. Se debe señalar asimismo que los únicos trabajos seguidos en la villa en 1815 se acometieron en ausencia del Príncipe de la Paz, desplazado por orden del pontífice a Pésaro entre septiembre de 1814 y octubre de 1815 a causa de la insistencia de Fernando VII al Gobierno pontificio para que impusiera salir de Roma al valido ${ }^{\text {. }}$.

La única fuente para conocer las excavaciones dirigidas por Celles es una publicación del arqueólogo y profesor de la Universidad de la Sapienza Lorenzo Re, de 1816, y en ella se ocupa mayormente de la explicación de la pieza clave de la colección de objetos antiguos de Godoy, el herma de Sócrates y Séneca, y en menor medida de los pasos que llevaron a su descubrimiento ${ }^{9}$. Además la vaguedad de su relato, falto de referencias cronológicas precisas, hace difícil situar con mayor exactitud todas las labores arqueológicas que señalaremos.

Antes de ver con más detalle los trabajos arqueológicos del Príncipe de la Paz y Antonio Celles, cabe indicar que el favorito de Carlos IV no se disponía a horadar un terreno virgen. A las ruinas supervivientes de los estragos del tiempo, visibles dentro de los límites de la altura del monte Celio, se sumaban los diversos restos desenterrados en el perímetro de la propia Villa Celimontana a lo largo de los siglos y sobre todo durante el Renacimiento: con toda probabilidad los Mattei contaron en su colección de antigüedades romanas con már-

${ }^{6}$ Carlo Fea puntualiza en 1820 Il restante (de la colección Mattei) venne in parte accresciuto dal nuovo possessore onde resta ancor ricca di monumenti di antica scultura. Il Signor Principe della Pace cui spetta se n'è occupato in modo che non gli rimane a desiderare il suo antico splendore. C. Fea, Descrizione di Roma antica e moderna e de'suoi contorni, tomo II, Roma, 1820, p. 309. Algunas de las antigüedades de la villa del monte Celio vienen recordadas en Maria Pasolini, "Villa Mattei e i giardini di Roma”, Roma, n. ${ }^{\circ}$ 4, Roma, 1925, p. 175.

7 Alicia M. ${ }^{a}$ Canto, La arqueología española en la época de Carlos IV y Godoy, Madrid, 2001.

8 Emilio La Parra, Manuel Godoy. La aventura del poder, Barcelona, 2002, pp. 436 y 437.

9 Lorenzo Re, Seneca e Socrate erme bicipite trovato da $S$. A. S. il Principe della Pace nelle scavazioni della sua Villa Celimontana già Mattei, Roma, 1816. Nosotros hemos utilizado la edición posterior, del mismo autor, "Illustrazione dell'erme bicipite di Seneca e Socrate", Pontificia Academia Romana de Arqueologia, I, 2, Roma, 1823, pp. 159-188. moles encontrados allí mismo y en otros terrenos que poseían alrededor de Roma y en la región del Lacio, aunque en los inventarios no se especifique su procedencia ${ }^{10}$. Podemos citar algunos ejemplos de estos descubrimientos anteriores a la época de Godoy.

La referencia más antigua se remite a cuando la villa todavía era la vigna vecchia de la familia Palluccelli, de la que se sacaron una gran cantidad de piedras y mármoles antiguos en 1537, y entre 1544 y 1546, columnas y arquitrabes de cipolino que Paolo III destinó a la construcción que Sangallo efectuaba de la Sala Regia del Vaticano, tal vez provenientes de las ruinas de un templo $^{11}$. A finales del siglo XVII, bajo el pontificado de Inocencio XI, vino a la luz un ninfeo de pequeñas dimensiones que en el momento se describió como un Tempio di figura bislunga con tre pilastri per parte di struttura antichissima il che si conosceva dal pavimento a mosaico e dalla struttura sopra la volta di materia laterizia. Un descubrimiento asociado a la Statio Cohors $V$ Vigilum -con sede en el Celio-, el de una capilla construida en el 113 d.C., tuvo lugar en la villa en 1735, tres años después de que una nueva búsqueda de materiales en los jardines localizara dos columnas de portasanta, una de ellas con una inscripción ${ }^{12}$. En realidad, como en el apartado correspondiente se dirá, no es descabellado relacionar además de los de 1820 todos los otros descubrimientos citados con los vestigios restantes del cuartel de la V cohorte sobre el Celio.

\section{PRIMEROS HALLAZGOS EN LA VILLA: EL CALDARIUM}

Uno de los cambios proyectados en la Villa Mattei afectaba al tamaño del palacete renacentista de Giacomo Del Duca, que al valido de Carlos IV le resultaba angosto y poco luminoso, debido a lo cual dispuso que se ampliara el edificio: trabajando en los cimientos de éste los operarios se toparon con muros del periodo romano y con un caldarium, que en palabras de Lorenzo Re, Bastò questo per risvegliare in Lui il genio delle scavazioni ${ }^{13}$. Podemos apuntar que el espíritu que se despertó en Godoy tendría seguramente más carácter de anticuario que de arqueólogo y que enseguida atisbó la posibilidad de enriquecer su palacio con las piezas que desenterrara.

\footnotetext{
${ }^{10}$ Maurizio Borda, "Sculture antiche a Villa Celimontana", Capitolium, n. ${ }^{\text {2 } 2,1956, \text { p. } 48 .}$

${ }^{11}$ Paola Hoffmann, Le ville di Roma e dei dintorni, Roma, 2001, p. 233.

${ }^{12}$ G. B. de Rossi, "Le stazioni delle sette coorti del vigili nella città di Roma”, Annali dell'instituto di correspondenza archeologica, n. ${ }^{\circ}$ 30, Roma, 1858, p. 290.

${ }^{13}$ L. Re, "Illustrazione dell'erme...", op. cit. n. 9, pp. 160 y 161.
} 


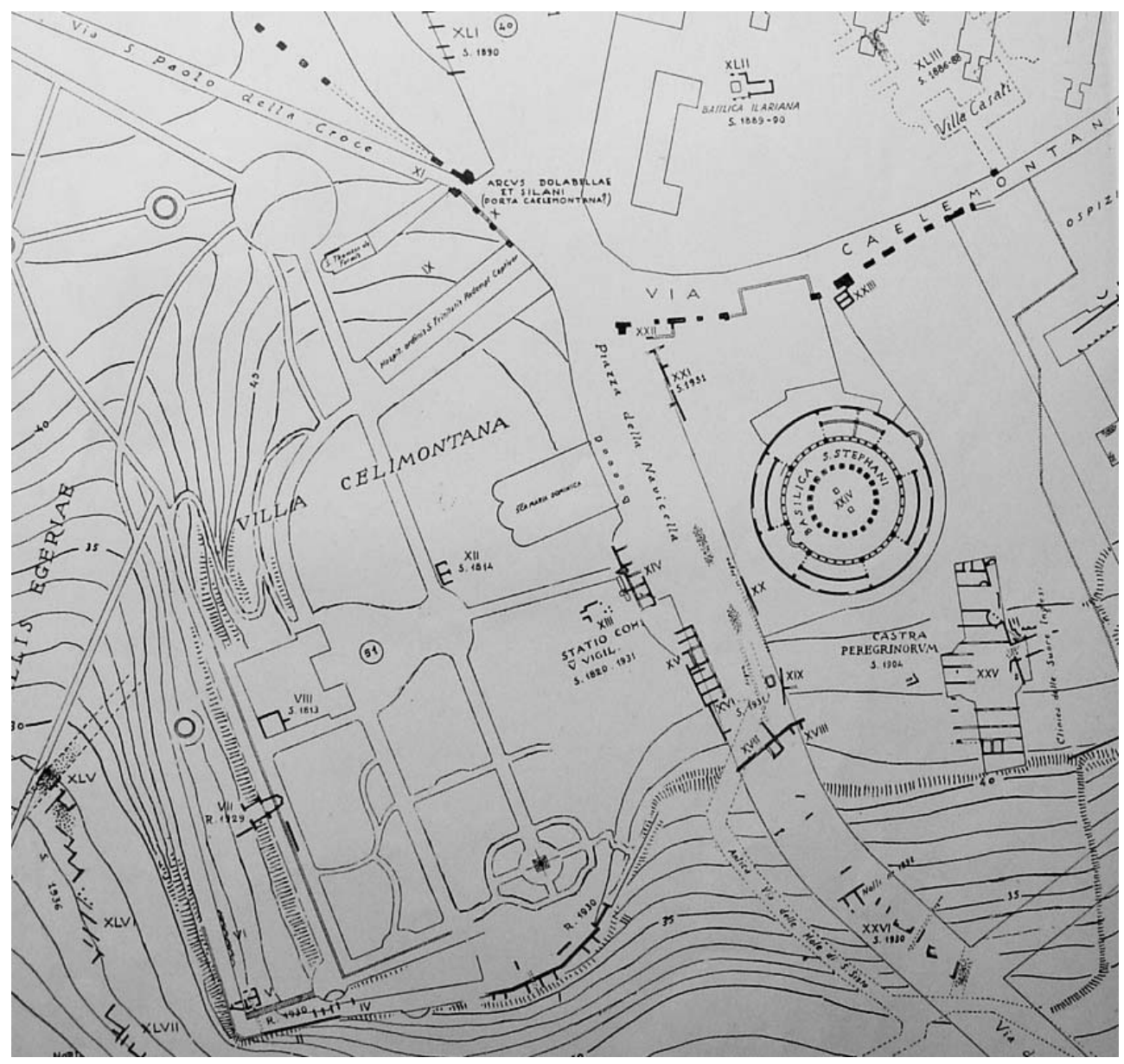

Figura 2. R. A. Lanciani, Forma Urbis Romae, 1893-1901, fol. 36.

En páginas precedentes se señaló que las primeras ruinas romanas ocultas en el subsuelo de la villa que se encontraron en época de Godoy lo fueron de modo accidental, mientras se reformaba la estructura del palacio en 1813; la mención de L. Re es muy escueta: nè voleasi disporre gli oggetti a guisa di magazzino: s'ingrandisce dunque, en el fondare i muri della nuova fabbrica, scopronsene degli antichi di buonissima maniera, e una stufa di quella costruzione, che incontrasi al solito nelle rovine delle case de' nostri antichi ${ }^{14}$. Pese a que en la guía de Roma de G. B. Cipriani se sitúa la reconstrucción del edificio Mattei por Celles en $1815^{15}$, sin duda el arquitecto catalán venía proyectando las obras a realizar desde el momento mismo de la compra de la villa por el Príncipe de la Paz, con el que comenzó a colaborar en

14 Íd., p. 160

${ }^{15}$ G. B. Cipriani, Descrizione itineraria itineraria di Roma, Roma, 1838, vol. II, p. 30. ese año de 1813; a petición de éste dirigiría a los trabajadores que debían transformar su palacio en un edifico amplio y luminoso, gracias a lo cual pudo ser testigo de este hallazgo inicial. Como arquitecto formado en la admiración de los monumentos romanos, no dejó escapar la oportunidad de dibujar el caldarium, probablemente perteneciente a una vivienda, dispuesto entre los muros de antigua factura ${ }^{16}$ : los diseños, nos informa Re, eran muy exactos y se los cedió a Manuel Godoy, que en 1816, tras el regreso de Celles a España, todavía los conservaba. Por su parte, Lorenzo Re no consideró necesario hacerlos grabar, al igual que los demás que componían su volumen del herma bicípite, porque nada mostraba que no se asemejara a los caldaria presentes en

${ }^{16}$ Un ejemplo de baños construidos dentro de un contexto habitacional es el de la Casa del Centenario de Pompeya, excavada en 1879. E. Fabbricotti, "I bagni nelle prime ville romane", Cronache pompeiane, n. ${ }^{\circ} 2$, 1976, p. 29 y ss. 


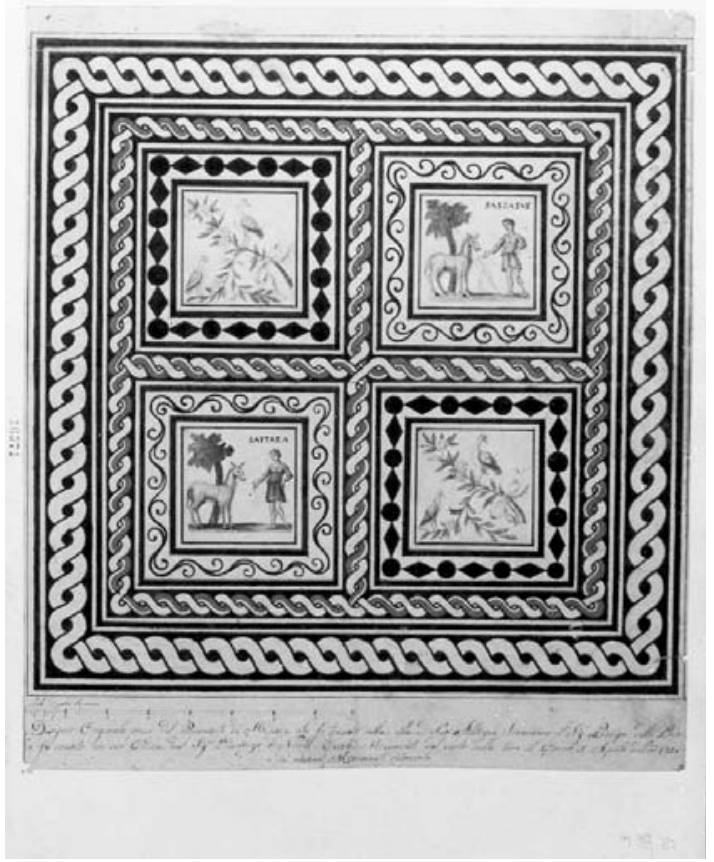

Figura 3. Antonio Celles. Disegno Originale preso dal Pavimiento di Mosaico... 1814. Roma. BIASA. R.XI.50.VII.5.

otras publicaciones. En la Forma Urbis de R. A. Lanciani aparece este descubrimiento ubicado en la parte posterior del palacio, en su ala izquierda ${ }^{17}$. Asimismo dispone el de los pavimentos detrás de la tribuna de la iglesia de Santa María in Domnica -nominada asimismo Navicella-, siendo los dos únicos hallazgos de Celles que contextualiza (Fig. 2).

\section{LOS DOS PAVIMENTOS (SIGLOS III-IV d.C.)}

Poco tiempo hubo de esperar Celles para volver a poner en práctica sus conocimientos en materia arqueológica: en 1814, rebajando la tierra del área comprendida entre el palacio y la Navicella para abrir un camino de entrada vieron la luz dos estancias decoradas con pavimentos de diferente calidad, uno de mosaico, "de unos 17 palmos en cuadro" y el segundo, más deteriorado que el anterior, en opus sectile ${ }^{18}$. Ambos fueron inmediatamente sacados y limpiados, y tras ser restaura-

${ }^{17}$ R. A. Lanciani, Forma Urbis Romae, Milán, 1893-1901, f. 36

${ }^{18}$ En el volumen de Re se lee altro a scompartimenti di varie pietre di grazioso e nuovo disegno, e di esattissimo lavoro, molto più danneggiato però del primo. L. Re, "Illustrazione dell'erme...", op. cit. n. 9, pp. 161 y 162.

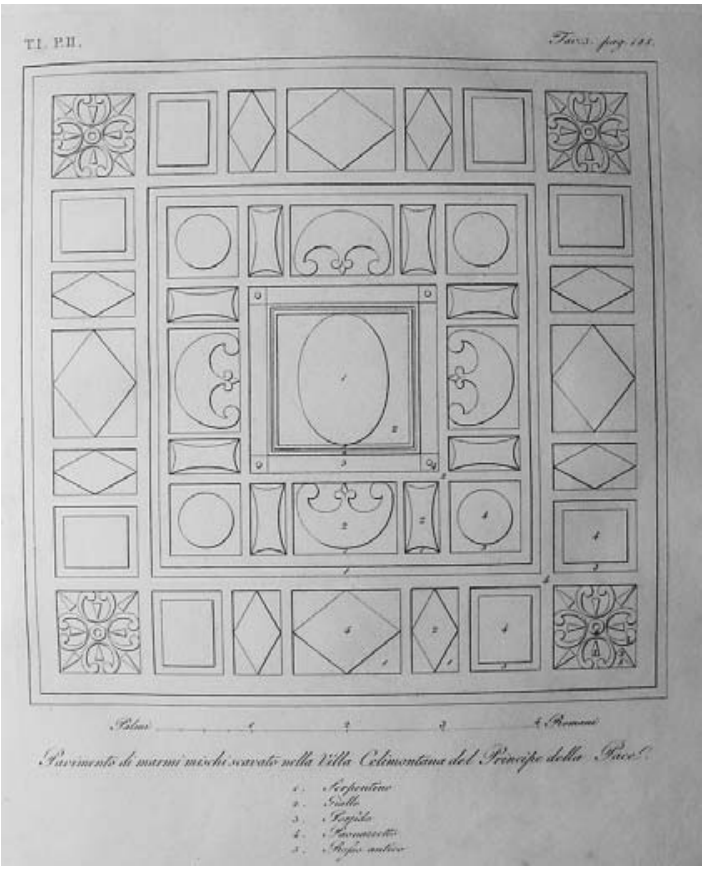

Figura 4. L. Re, Illustrazione dell'erme bicipite di Seneca e Socrate, 1823, lám. 3.

do por Vincenzo y Nicola Cocchi, el mosaico pasó a decorar una de las estancias del palacio, sala que desde 1926 forma parte de la Biblioteca de la Real Sociedad Geográfica Italiana y donde aún se conserva el pavimento musivo.

El mosaico ${ }^{19}$ según L. Re no constituía un trabajo muy fino, pero su ornamentación le parecía fuera de lo común y merecedora de ser reproducida por los artistas contemporáneos en sus obras. Celles realizó una pequeña acuarela del mismo (Fig. 3), que posteriormente sería grabada en la publicación de aquél por G. Brun ${ }^{20}$. El pavimento se halla encuadrado por una banda trenzada en blanco y negro con grandes círculos y otra de menor tamaño con pequeños ojos en blanco y rojo sobre un fondo negro, que además divide en cuatro la parte cen-

19 Acerca de este mosaico se puede consultar Marion E. Blake, "Mosaics of the Late Empire in Rome and vicinity", Memoirs of the American Academy in Rome, XVII, Nueva York, 1940, p. 109.

${ }^{20}$ L. Re, "Illustrazione dell'erme....", op. cit. n. 9, lám. 4, p. 188. Al pie del dibujo original viene escrito: Disegno originale preso dal Pavimento di Mosaico che fu trovato nella villa di Sua Altezza Serenissima il Sig. Principe della Pace e fu cavato con suo Ordine dal sig. Vincenzo e Nicola Cocchi Mosaicisti nell'anno 1814 e dal medm.i. Mosaicisti restaurato. Debemos establecer la fecha de su hallazgo antes del mes de abril, cuando aproximadamente apareció la escultura bifronte. 


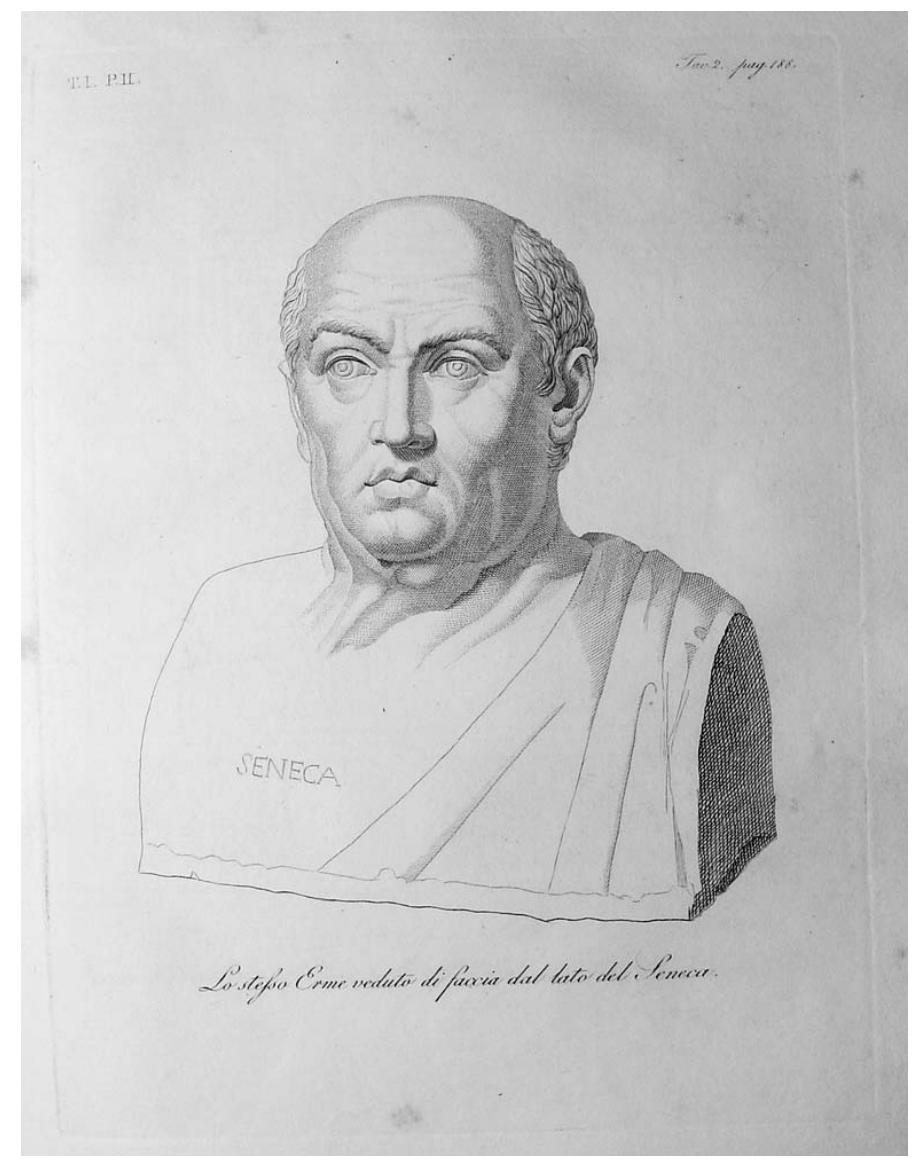

Figura 5. L. Re, Illustrazione dell'erme bicipite di Seneca e Socrate, 1823, lám. 2.

tral del mosaico; cada campo, a su vez, posee su propio borde decorativo en blanco y negro, lo que contrasta con la iconografía a color que limitan. Una fila de círculos y rombos forma la estructura de las imágenes del primer y cuarto cuadros, completamente iguales, de dos pájaros encaramados en las ramas de un rosal; los otros dos compartimentos, individualizados por unos sencillos adornos, muestran un cuadrúpedo junto a un árbol encorvado, olfateando la mano de una figura humana vestida con túnica de manga larga. Sobre ambos personajes aparecen los nombres de Pascasus y Sattara, y tradicionalmente se consideraron los de los dos animales, presumiblemente caballos ganadores de las carreras, y aquéllos se contemplaron como los aurigas que los montaban.

El grabado del suelo de opus sectile ${ }^{21}$ enseña solamente un cuarto de éste, al repetirse en las otras tres partes la misma decoración; la variedad de los mármoles utilizados en su ejecución (indicado mediante la numeración de las

\footnotetext{
${ }^{21}$ Id., lám. 3, p. 188.
}

figuras geométricas que forman el piso), como son el Serpentino, el Porfido, o el Giallo, entre otros, provocó los elogios del arqueólogo de la Sapienza, quien juzgaba de mejor factura esta pieza que la precedente (Fig. 4).

Ambos pavimentos se han datado en el siglo III d.C., el de mosaico por la singularidad de su doble banda serpenteante, que apunta a esa época, y el segundo por haberse encontrado junto a él aunque igualmente podría ampliarse esa fecha al IV d.C. En el momento de su descubrimiento no se puso en duda que pertenecieran al piso de una villa aristocrática: Re se la asignaba a un amante de las carreras que había querido inmortalizar en un mosaico la memoria de las victorias de sus caballos preferidos e igualmente A. M. Colini, que ha analizado exhaustivamente el área del Celio, sugiere que por su riqueza, y por su naturaleza, no pueden ser explicados de otro modo que refiriéndolos a una suntuosa vivienda ${ }^{22}$. Sin embargo, la temática propuesta entonces plantea

${ }^{22}$ A. M. Colini, Storia e topografia..., op. cit. n. 5, p. 228. 
algunos inconvenientes ${ }^{23}$ : en primer lugar, los animales que iguran en el mosaico no se asemejan a caballos (ni siquiera portan bridas u otros elementos de monta, como suele ser habitual en la iconografía de los caballos de las carreras), sino que más bien parecen alguna clase de bestia asilvestrada, a la que los personajes humanos avecinan sus manos, tal vez con el propósito de dársela a olisquear para amansarla, o como símbolo de su dominio sobre ella. En su dibujo, Antonio Celles, seguramente con la intención de imbuir al mosaico la belleza que le faltaba, y de un semblante de mayor clasicismo, proporcionó a los animales un aspecto más equino del que poseen en la pieza original, pero identificándolos con asnos, o mulas, antes que con caballos; por el contrario, G. Brun, aún desvirtuándolos les mantuvo en su posterior grabado una apariencia más fiera. En segundo lugar, los nombres de Pascasus y Sattara no responden a patronímicos comunes de los caballos de carreras, consistente en características psicológicas o físicas, nombres de otras criaturas, de dicoses y héroes, de virtudes, etc. ${ }^{24}$. Ni siquiera responden a apelativos de animales, sino que por ejemplo, Pascasus significa "nacido en Pascha- o Pesach"- (una denominación temprana de Roma en el ámbito cristiano), y se encuentra con frecuencia en la onomástica cristiana, y desde el siglo V d.C., por transmisión cultural, en la hebrea ${ }^{25}$. Luego bien podrían ser los nombres de ambos individuos, quienes por cierto tampoco lucen los atavíos y aparejos típicos de los aurigas. Con todo, esta interpretación no entra en contradicción con la posibilidad, más que plausible -a pesar de que recientemente su hallazgo se ha puesto en relación con el cuartel que albergaba a la Cohors $V$ Vigilum, tema del que trataremos más adelante-, de que el pavimento musivo adornara la estancia de una villa; la iconografía del mosaico podría hablarnos incluso del credo religioso de su propietario.

\section{UNA BÓVEDA ARRUINADA DESPIERTA CIERTA POLÉMICA}

En el mismo periodo encontramos a Celles abriendo una nueva excavación entre la iglesia de Santo Tommaso in formis y el granero de la villa, en el extremo norte

${ }^{23}$ Debo agradecer a la profesora Beatrice Cacciotti que me indicara sus dudas acerca de la interpretación tradicional del mosaico, y me señalara las claves para un razonamiento más acertado, que desarrollo a continuación.

${ }^{24}$ J. M. C. Toynbee, Animals in Roman life and art, Baltimor-London, 1973, p 178 y ss.

${ }^{25}$ Véase Margaret H. Williams, "Jewish festal names in Antiquity. A neglected area of onomastic research", Journal for the Study of Judaism, n'. 1, XXXVI, 2005, pp. 21-40. de ésta ${ }^{26}$. La zona de excavaciones no nos la precisa Lanciani en su Forma Urbis; aún así podemos especular que el granero no estaría lejos del muro que cerraba el recinto por el lado de dicha iglesia, lo que sitúa los trabajos de Antonio Celles en el área del interior de la Villa Celimontana colindante con el arco de Dolabella. En esta ocasión hubo que apresurarse en retirar los materiales porque se había cavado a una gran profundidad y los restos constructivos amenazaban con venirse abajo; por ello, a pesar de que se auguraban importantes descubrimientos en esa zona, los trabajos fueron interrumpidos y se recubrió de tierra lo excavado. Como resultado de estas labores se sacaron a la luz los restos de la decoración de una bóveda, consistentes en teselas esmaltadas muy deterioradas por la acción del fuego y de la humedad, y bajo ellos un fragmento de columna con estrías en espiral de alabastro oriental, a partir del cual el escultor Ramón Barba, protegido de Godoy, talló un vaso decorativo. Acerca de la época y de qué tipo de edifico se había encontrado allí surgieron diversas opiniones; algunas de las personas implicadas en la excavación, tal vez incluido el propio Celles, sostenían que un ábside de esas características, es decir, recubierto de mosaico esmaltado, tenía que haber formado parte de una construcción cristiana del siglo IV, o como máximo del V, y que por lo tanto, aunque hubiese existido la posibilidad de seguir adelante con los trabajos comenzados, cualquier investigación ulterior resultaba inútil. Por su parte Lorenzo Re, quién fue testigo del hallazgo, disentía de este parecer en la publicación de 1816. Defendía que ya antes de la era cristiana los antiguos hacían uso del mosaico en las soluciones abovedadas, para cuya demostración se atenía a la Historia Natural de Plinio y a los escritos de Estacio. Por si el juicio de estas autoridades no bastase, todavía añadía que la sola contemplación de los muros arruinados que sostenían la bóveda y de lo que quedaba de su revestimiento, le inducía a pensar que todos esos vestigios componían los restos de un edificio levantado "en los mejores tiempos del Imperio", incluso previo a la construcción que contenía los dos pavimentos mencionados. Debido a la escasez de datos sobre este asunto, Colini aventura que dicho ábside pertenecería a un ninfeo emplazado en el espacio que surgía detrás de la iglesia de Santo Tommaso in Formis.

\section{EL HERMA DE SÓCRATES Y SÉNECA}

Las obras de renovación proseguían en 1814 tanto en el palacio como en los jardines de la Villa Celimontana y

${ }^{26}$ Acerca de esta iglesia, Alia Englen (ed.), Caelius I. Santa Maria in Domnica, San Tommaso in Formis e il clivus Scauri, Roma, 2003. 
gracias a ellas sobrevino el descubrimiento que le otorgaría más prestigio al Príncipe de la Paz. Mientras se practicaba una camino de comunicación entre las dos vías que desde las puertas de acceso a la villa conducían a su plaza central, en las proximidades de Santa María in Domnica y contiguo al lugar en el que aparecieron los pavimentos, se encontró junto algunos huesos humanos un herma bifronte ${ }^{27}$; al quitar la tierra adherida al mármol se pudo leer la inscripción que ambos personajes tenían en el pecho: la del rostro barbado, escrita en griego, indicaba que se trataba de Sócrates, mientras que el otro epígrafe, en latín, decía "SENECA". Por primera vez se disponía de una prueba material del aspecto físico del filósofo hispano, "un personaje sin barba, de formas relajadas más que gruesas, de fisonomía grave, modesta, y digna, de unos 55 años" ${ }^{28}$ (Fig. 5). No fue éste el único objeto que se consiguió en aquel punto, pues en el invierno de 1815 se reemprendieron las excavaciones, con resultados bastante menos notorios: de entre una gran cantidad de ceniza y cobre quemado se rescataron tres piezas de este metal bien conservadas, un praefericulum también de cobre, deteriorado por el fuego, diversas medallas irreconocibles (a excepción de dos en buen estado, una de Julia Mammea y otra de M. Julio Filipo César, conocido como Filipo el Árabe), una lucerna metálica entera y numerosos sillares de mármol africano. La elegancia y la originalidad de la lucerna, cuya tapa y asa se adornaban con una concha marina y una paloma respectivamente, llevaron a Re a hacer grabar la pieza, con la creencia de que por estos símbolos, si hubiera de estar consagrada a un Dios, lo estaría a Venus ${ }^{29}$.

Aquí finalizaron las intervenciones arqueológicas en la Villa Celimontana del pensionado Antonio Celles, ya que poco tiempo después regresaba a España. De todas

27 Nibby indica como su descubridor al Ingeniero Comunal Paolo Lanciani. Celles dispuso de la colaboración de expertos italianos durante las excavaciones, como hemos visto en el caso de Lorenzo Re, por lo que no sería extraño que el personaje citado las presenciara y aconsejara al arquitecto pensionado en ellas. A. Nibby, Itinerario di Roma e suoi dintorni, Roma, 1886, p. 89. Otra atribución equivocada es la de Luigi Càllari, quien adjudica a la princesa Marianna de Holanda el hallazgo del herma en 1851 junto a varias tumbas y sarcófagos. Luigi Càllari, Le ville di Rome, Roma, 1934, p. 143. Acerca de la actividad arqueológica de dicha princesa Luigi Canina, La prima parte della Via Appia dalla Porta Capena a Boville, Roma, 1853. La licencia de las excavaciones de 1851 en la Villa Mattei está en ASR. Camerlangato. Parte II (1824-1854). Título IV. Antichità e Belle Arti. Sig. 305.

${ }^{28}$ En relación con otros descubrimientos de hermas en el monte Celio, AA. VV., "Celio", en Beatrice Palma, Pirro Ligorio e le erme di Roma, Roma, 1998, pp. 31-86.

${ }^{29}$ La lámpara de metal queda reproducida en la primera página del texto de Re publicado por la Pontificia Academia de Arqueología en 1823. las excavaciones que llevó a cabo por cuenta de Godoy fue sin duda la que culminó con el hallazgo del herma la que mayor atención despertó en los círculos intelectuales romanos, por el carácter de la pieza obtenida y la exhibición que hizo de ella el Príncipe de la Paz. El primer paso que dio éste fue someter la pieza al juicio de la Academia de Bellas Artes de Roma, la Academia de San Luca, para conocer su valor. Godoy era miembro de honor de ella desde 1813 y en noviembre de ese año había escrito a su Presidente, el escultor Canova, solicitándole un examen similar de otra de las piezas de su colección: había adquirido recientemente un cuadro, de una "Madonna che tiene il Santo Bambino in braccio con due angioli in piedi", y rogaba a Canova que lo presentase ante los académicos de San Luca para saber su opinión sobre quién podía ser su autor, aunque se ignora si el artista italiano respondió a su petición ${ }^{30}$.

La Academia romana confirmó la antigüedad de la escultura bifronte en la reunión del 22 de abril de 1814, si bien la calificó como una escultura de segundo orden ${ }^{31}$. Insatisfecho de la resolución se dirigió hacia el arqueólogo Lorenzo Re, al que hemos venido citando a menudo, cuyo seguimiento de todos los trabajos realizados en los términos de la antigua Villa Mattei y su amistad con Celles, lo convertían en la persona idónea para estudiar en profundidad el herma. Re se ocupó de que la talla fuera grabada y de ilustrar las imágenes con una disertación en la que trataba de resolver algunos interrogantes acerca de ella (Fig. 6). A la vez respondía claramente con su discurso al dictamen de la Academia romana y elogiaba la figura de Manuel Godoy, su "Illustre Ritrovatore", sin renunciar tampoco al mérito de ser el primero en dar a conocer la fisonomía del filósofo estoico Séneca ${ }^{32}$.

${ }^{30}$ Alessandro Bocca, “Godoy principe...”, op. cit. n. 1, p. 48.

31 Ver AA. VV., La imagen de Manuel Godoy, Junta de Extremadura, 2001, p. 183, n. 231. En esta sesión coincidieron nombres tan conocidos de la Historia del Arte como el de Valadier, Thordwalsen, Pacetti, y los españoles José de Madrazo y José Aparicio. El juicio sobre el herma dice así: Ad istanza del S.r. Principe della Pace, fu essaminata la sua Erme doppia recentemente scavata che offre i due ritratti di Socrate e Seneca; ed in riguardo dell'Arte fu giudicato essere scultura antica di seconda clase. ASL. "Registro delle Congregazioni di Belle Arti dell'anno 1812-1819”, vol. 59, 22 Aprile 1814. La fecha en la que la Academia de San Luca emitió su parecer confirma la opinión de que el herma se encontrara a comienzos de dicho año.

${ }^{32}$ El tono de lisonja se expresa en los siguientes términos: $E$ con ragione dee andare glorioso l'Illustre Ritrovatore, tanto più che appartenendo anch'Egli alla Betica, viene ad essere, come già dissi, a quel grand Uomo congiunto co'vincoli di nazionalità non solo, ma di patria; e può riguardarsi come una circostanza singolarissima, che questo Erme sia sfuggito a tanti indagatori diligentissimi, appunto per cader nelle mani di uno, che più di tanti altri conosceane il merito, e più di tutti avea diritto di possederlo. L. Re, "Illustrazione dell'erme...", op. cit. n. 9, p. 178. 


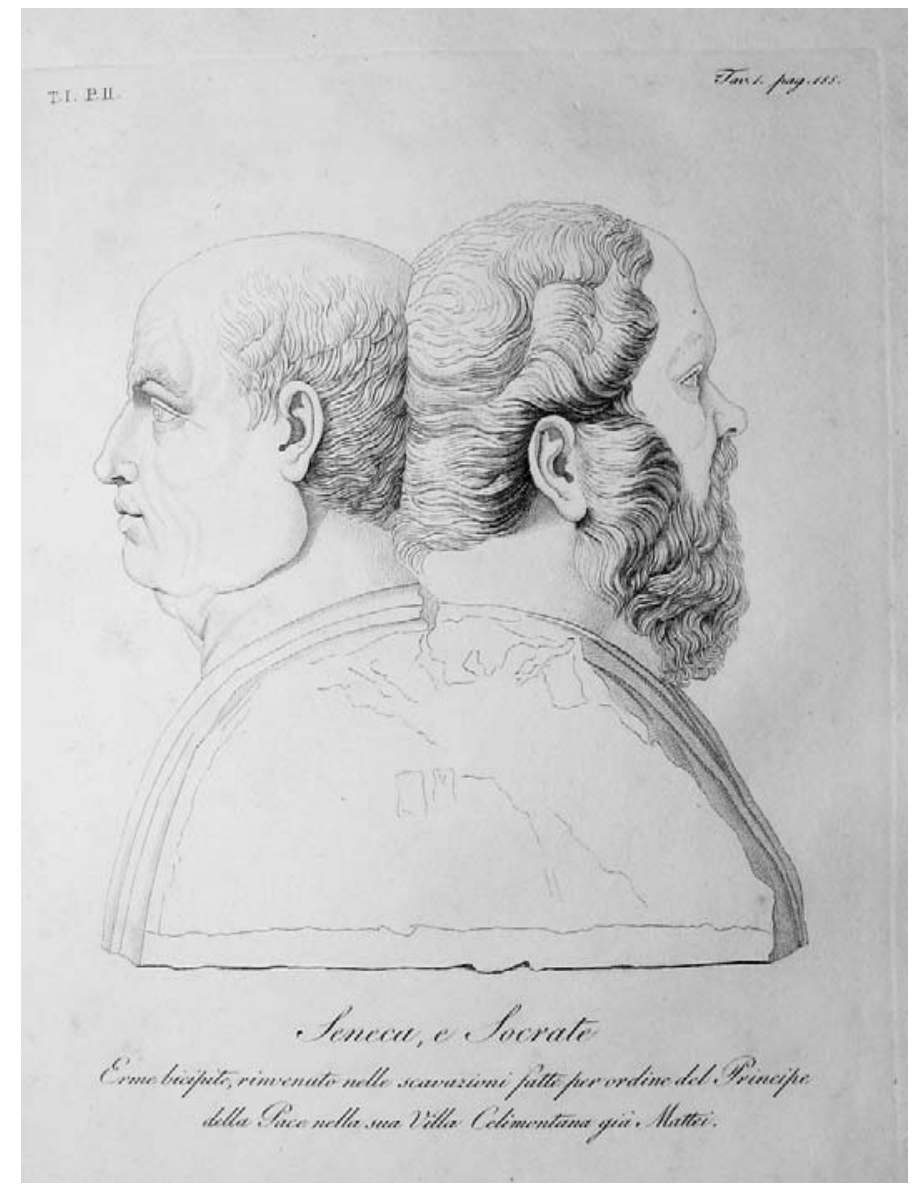

Figura 6. L. Re, Illustrazione dell'erme bicipite di Seneca e Socrate, 1823, lám. 1.

El volumen como sabemos se publicó en 1816, y en la sesión del 1 de agosto de ese mismo año de la Academia Romana de Arqueología tuvo lugar su lectura, de la que se hace eco el anticuario G. A. Guattani entre los demás eventos culturales y arqueológicos del momento ${ }^{33}$; en 1823 la obra se incluyó en el primer tomo que dicha institución editó con diversos artículos de sus miembros y todavía en 1824 las Memorie romane di Antichità e Belle Arti presentaban un resumen del escrito de Lorenzo $\mathrm{Re}^{34}$. Por lo tanto, parece que el propósito del valido extremeño de divulgar la trascendencia de la escultura de su propiedad quedó cumplido.

¿Cuáles eran las cuestiones a resolver acerca del herma de Sócrates y Séneca, de las que Re nos informa

${ }^{33}$ G. A. Guattani, Memorie enciclopediche sulle antichità e belle arti di Roma per il 1816, Roma, 1817, p. 39.

${ }^{34}$ L. Cardinali, G. Melchiorri, P. Visconti, C. Cardinali, Memorie romane di Antichità e Belle Arti, vol. I, Roma, 1824, pp. $158-160$. en su pequeño volumen? Por de pronto, su autenticidad había sido ratificada, pero todavía quedaba por saber si la inscripción que llevaba grabada sobre el pecho era auténtica o por el contrario una falsificación; tampoco se conocía su época, y en cuanto a su iconografía, en nada se asemejaba a los retratos de Séneca difundidos hasta el momento. El encontrado en la Villa Celimontana, de $28 \mathrm{~cm}$ de altura, era absolutamente diverso al personaje barbado calificado como Séneca hasta entonces, siendo casi calvo y con el rostro rasurado y carnoso ${ }^{35}$. Lorenzo Re hizo trasladar a su vivienda el herma para analizarla, en donde otros especialistas tuvieron acceso a ella y extrajeron iguales conclusiones que el arqueólogo italiano.

Aseguraba que las letras del epígrafe con el nombre de Séneca, por su forma, la particularidad de su inci-

35 Consúltese Carl Blümel, Römische Bildnisse, Berlín, 1933, R. 106, lám. 71; Huberta Heres, Römische Porträts, Berlín, 1982, pp. 10-12, nº 9. 
sión y la analogía con otros textos del periodo en el que ubicaba el herma, eran antiguas y que el estilo de la escultura coincidía cronológicamente con el de la inscripción; continuaba demostrando su veracidad argumentando que no existen motivos para llevar a cabo una falsificación y en su énfasis por aclarar este punto nos hace sospechar que acaso el Príncipe de la Paz fuera objeto de acusaciones en este sentido. En cuanto a la datación de la talla, la factura de los epígrafes y el modo de trabajar el mármol lo conducían a la etapa de los Antoninos, aunque apuntaba que seguramente fuese una réplica de un bello original del siglo de Nerón.

Resueltos estos interrogantes, le llamaba la atención que el semblante del hombre representado en la escultura no correspondiese con las noticias que los autores clásicos transmitían del filósofo hispano, ni su aspecto con el de las cabezas del Museo Capitolino y el de Portici que desde hacía tiempo comenzaban a considerarse falsas. Que se trataba de L. Anneo Séneca, y no de M. Anneo Séneca el Retórico, lo razonaba por la presencia junto a él de la cabeza de otro filósofo, Sócrates, y porque el Séneca por excelencia era el preceptor del emperador Nerón. No obstante, la representación en el herma de un personaje sano y robusto contradecía las referencias de Tácito en relación a su naturaleza enfermiza y su debilidad, de lo que cabría esperar un tipo de imagen acorde con esta condición ${ }^{36}$; la interpretación de este hecho por parte de Lorenzo Re incidía en la lectura excesivamente estricta que se había hecho de los textos, que por calificarlo de achacoso, se le había creído moribundo y deforme, mientras que su estado de salud no le impediría en ocasiones aparecer físicamente robusto. Para apoyar esta conjetura insertaba en su opúsculo una carta del doctor de Mattheis, socio también de la Pontificia Academia Romana de Arqueología, quien a petición suya efectuó un estudio "médico" del busto, concluyendo que correspondía a una fase en la que Séneca aún no había caído en desgracia y disfrutaba de buena salud $^{37}$.

El propio descubrimiento del herma ponía fin a las inciertas atribuciones como cabezas del filósofo a las existentes en diversas galerías de Italia: Lorenzo Re no dejaba de señalar su originalidad y se lamentaba de que la fuerza de la tradición iniciada por el anticuario Fulvio Orsino mantuviera durante más de tres siglos la

\footnotetext{
${ }^{36}$ En estas líneas de la disertación de L. Re es donde mejor observamos esa característica típica del anticuario de recurrir a las fuentes para explicar los materiales arqueológicos, y de cómo se deben resolver continuamente las contradicciones que plantea este confronto.

${ }^{37}$ L. Re, "Illustrazione dell'erme...", op. cit. n.9, pp. 180188.
}

equivocada percepción de la imagen de Séneca. Efectivamente, sólo en Roma existían varias testas atribuidas al estoico hispano en las villas Medici, Albani, Pamphili ${ }^{38}$-trasladada posteriormente al Museo Pío Clementino- y Borghese ${ }^{39}$ por su parecido a una de la colección Farnese a la que Fulvio Orsino había reconocido como de Séneca por su semejanza a una medalla poseída por el cardenal Bernardino Maffei ${ }^{40}$. Dicha medalla no se hallaba en ningún museo y no se tenían más noticias de ella que las difundidas por Giuseppe Fabri, quien, al explicar las efigies de los hombres ilustres recogidas en la obra de Orsino, narraba en la correspondiente a Séneca esta historia que con toda seguridad había copiado de las notas manuscritas de su autor $^{41}$. Por lo tanto, a partir de esa supuesta identificación de la cabeza del Palacio Farnese con el maestro de Nerón, se había creado un tipo iconográfico que perduraba todavía a comienzos del siglo XIX ${ }^{42}$. Uno de los pocos autores en poner en tela de juicio la autoridad de Orsino fue Winckelmann, quien se extrañaba de la multiplicidad de retratos de un filósofo que tuvo poca reputación entre los antiguos y de su representación con barba, una costumbre insólita en los tiempos en que vivió ${ }^{43}$. Algunos de estos bustos ya habían sido "desenmascarados"; por ejemplo, la estatua de mármol bigio de la Villa Borghese, de la que el anticuario alemán había comprendido la imposibilidad de adscribirla a Séneca, fue finalmente relacionada con la de un Pescador del Museo Pío Clementino por Ennio Quiri-

\footnotetext{
${ }^{38}$ Esta estatua ni siquiera es una pieza completa; originalmente era propiedad del prelado Ferrante Loffredo, quien solamente hizo colocarle una cabeza cuando se la donó al papa Clemente XIV (1705-1774).

${ }^{39}$ Otro conocido busto de Séneca de bronce se podía contemplar en la segunda mitad del XVIII en el Museo Ercolanense. Bronzi d'Ercolano, tomo I, láms. 35 y 36; Stefano De Caro, Il Museo Archeologico Nazionale di Napoli, Nápoles, 1994, p. 289.

${ }^{40}$ F. Orsino incluyó la reproducción de esta cabeza nominándola como Séneca en Imagenes et elogia virorum illustrium et eruditor, ex antiquis lapidibus et numismatibus expressa cum annotationibus ex Bibliotheca Fulvi Ursini, Roma, 1570, p. 74, $\mathrm{n}^{\mathrm{o}} .131$.

${ }^{41}$ En lo referente a esta cuestión, véase Ennio Quirino Visconti, Il Museo Pio Clementino, vol. III, Milán, 1819, pp. 80-86; Francis Haskell y Nicholas Penny, Pour l'amour de l'antique. La statuaire gréco-romaine et le goût européen 1500-1900, Hachette, 1988, pp. 68 y 69.

${ }^{42}$ Acerca del problema del tipo de retrato creído de Séneca hasta el XIX, bautizado como Pseudo Séneca, Barbara Nobiloni, "Villa Adriana", en Beatrice Palma (ed.), Le erme tiburtine e gli scavi del settecento. Uomini Illustri dell'antichità, I, 2, Roma, 1992, pp. 287 y 288.

${ }^{43}$ J. Winckelmann, Storia delle Arti del Disegno presso gli antichi, tomo II, Roma, 1783, lib. XI, cap. III, pp. 351-353.
} 


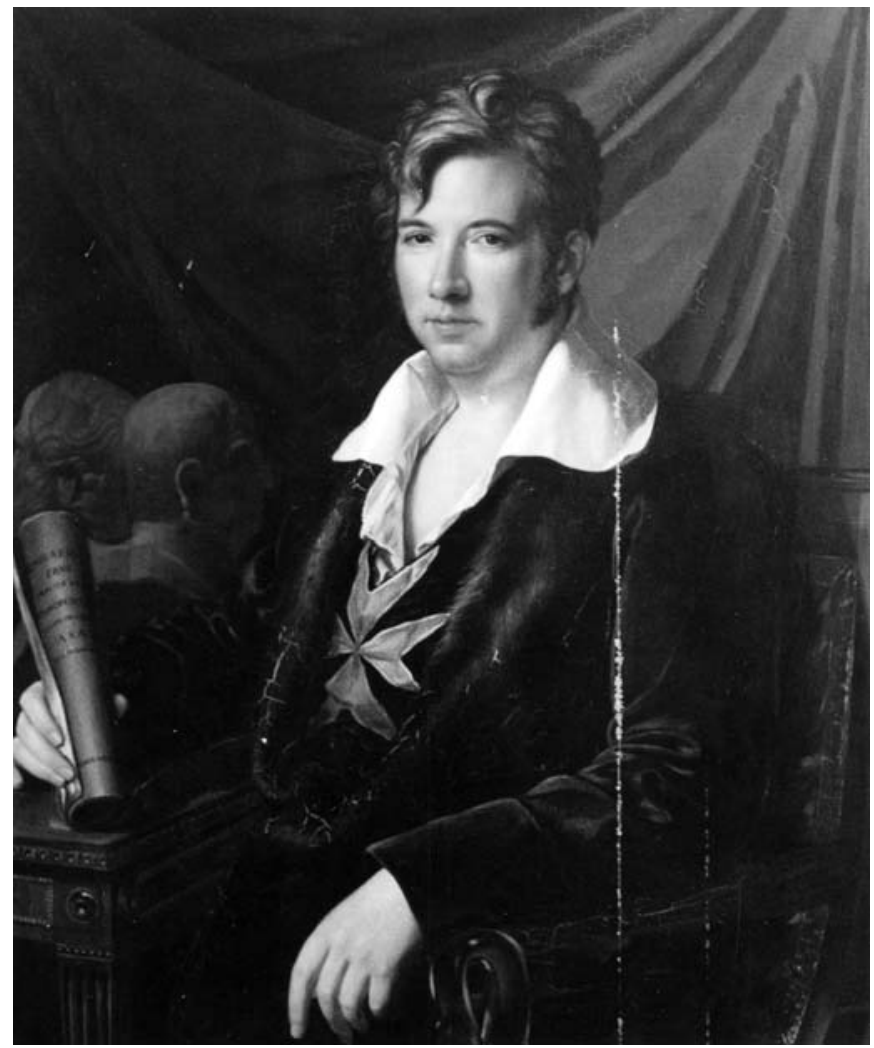

Figura 7. José de Madrazo. Manuel Godoy, Gentleman Archeologist 1816. Madrid. Real Academia de San Fernando.

no Visconti ${ }^{44}$, recuperando así su carácter inicial. No obstante, la obra de Visconti Iconografia romana (Roma, 1818) no incluyó entre las imágenes de Séneca comentadas el busto del filósofo descubierto por Celles, del que sin embargo sí añadía en la última página una lámina con el subtítulo Erme trovato ultimamente a Roma e portante il nome di Seneca. Este hecho encuentra su explicación en que Visconti no reconoció la nueva iconografía del filósofo hispano como la verdadera, a pesar de no discutir la antigüedad de la inscripción que portaba el herma.

La réplica de Lorenzo $\mathrm{Re}$, y por consiguiente de Manuel Godoy, al veredicto de la Academia de Bellas Artes romana se refleja tajantemente en la conclusión del escrito de 1816, donde se subrayaba la preciosidad del herma: Questo è quello, che fa scendere dal Vaticano, $e$ dal Campidoglio i Pseudoseneca, e sbalza dalle loro sedie curuli, che indegnamente occupavano e per sorpresa, tutti gli altri, che la Villa Albani, la Galleria Corsini, il Museo Ercolanense, ed altri luoghi cospicui tenevano in

${ }^{44}$ Ennio Quirino Visconti, Il Museo..., op. cit. n. 38, lám. 32, pp. $143-148$. venerazione: questo è quello, che obbliga a correggere tante descrizioni di Musei, di Dattilioteche, di Medaglieri, tante edizioni delle opere di quell'insigne Scrittore ${ }^{45}$.

No le bastaba al Príncipe de la Paz y de Bassano con colocar el doble busto en una de las salas de su palacio del monte Celio, sino que además se retrató junto a él en un óleo de 1816, localizado actualmente en la Real Academia de San Fernando de Madrid, cuyo autor, José de Madrazo, tituló Gentleman Archeologist ${ }^{46}$ (Fig. 7). En él

${ }^{45}$ L. Re, "Illustrazione dell'erme...", op. cit. n. 9, p. 178.

${ }^{46}$ Es el único retrato que se conserva del periodo en el que Godoy estuvo en el exilio, del que Madrazo había pintado otro cuadro en 1812; se encontraba en una colección privada de Perugia, en la que fue redescubierto en 1998 por J. L. Díez y dado a conocer en la exposición monográfica sobre el pintor celebrada en Madrid y Santander dicho año. En 2004 fue adquirido por la Real Academia de San Fernando de Madrid. AA. VV., La imagen..., op. cit. n. 28, p. 183, n. 230. Véase AA. VV., José de Madrazo (1781-1859), Santander, 1998, pp. 238-240; Isadora Rose-de Viejo, "La formación y dispersión de las colecciones artísticas de Manuel Godoy en Madrid, Roma y Parías (17921852)", en Emilio La Parra López y Miguel Ángel Melón Jiménez, Manuel Godoy y la Ilustración, Mérida, 2001, pp. 130 y 131. 
se plasma al favorito del rey Carlos IV en su nueva faceta ilustrada y arqueológica: en la mano derecha sujeta la obra de Lorenzo Re, mientras que en segundo plano aparece la escultura bicípite de Sócrates y Séneca. Las insignias y atributos de hombre de Estado que se despliegan en las obras anteriores que de Godoy podemos observar, entre otros lugares, en el Museo del Prado, o en el de la Real Academia de Bellas Artes de San Fernando, han sido dejadas atrás a favor de la representación del Príncipe de la Paz en el exilio italiano; en su nueva condición es el aristócrata que ofrece magníficas fiestas en los jardines de la Villa Celimontana, que es recibido en las casas de la nobleza de Roma, que acompaña a los reyes de España en los actos públicos, pero también quien pertenece a instituciones culturales, promueve las Bellas Artes y patrocina excavaciones arqueológicas. Es en definitiva el prototipo de caballero de la Roma napoleónica.

En las guías al uso en la Ciudad Eterna se describe cómo todos los materiales excavados bajo la dirección de Antonio Celles se veían distribuidos en el interior del palacio reformado por el arquitecto pensionado. Así, en la de Cipriani dice: "Nel riformato casino vedonsi quadri di scuola spagnola, pedestalli con iscrizioni, un musaico antico, l'erma di Seneca e Socrate, ed altre anticaglie rinvenute nei spianamenti fatti nella villa con la direzione dell'architetto spagnolo D. Antonio Celles nel 1815" ${ }^{47}$. Junto al compendio de Nibby acerca de la Roma de $1838^{48}$, es de las últimas referencias que tenemos de la posesión del herma por parte de Godoy: debiendo una gran suma de dinero a Felice Trocchi, tuvo que cederle la propiedad de la antigua Villa Mattei, como queda reflejado en un acta de venta de 1851 donde se recogen los cambios de propietarios que sufrió la villa en el siglo XIX ${ }^{49}$. Su traspaso se llevó a cabo mediante dos instrumentos jurados ante notario del 30 de abril de 1836 y 28 de febrero de 1840, ratificados en las actas del notario Fratocchi el 13 de diciembre de 1841. Interesado en recuperar la cantidad adeudada por Godoy y deseoso de desprenderse de una vivienda gravada por una fuerte hipoteca, Trocchi vendió inmediatamente la villa, de forma que un año después pasaba a manos de la marquesa María del Soccorso Tudo y Castelan y de sus tres hijos, los condes Carlo, Antonino y Curzio Stefanoni ${ }^{50}$.

${ }^{47}$ G. B. Cipriani, Descrizione itineraria..., op. cit. n. 15, vol. I, p. 41.

${ }^{48}$ Nibby, Roma nell'anno 1838, Roma, 1838-41, vol. IV, p. 948 .

${ }^{49}$ Carla Benocci, Villa Celimontana, Turín, 1991, p. 64, n. 80. Este documento de 1851 se encuentra en ASR., 30, Notai Capitolini, uff.1, Baccheti Filippo, n.258, Van Rossum Giovanni, acquisto della villa, atto del 7 giugno 1851, c. 259 rv.

${ }^{50}$ Carlo Pietrangeli, Guide Rionali di Roma. R. XIX. Celio. Parte seconda, Roma, 1987, p. 28.
El herma, sin embargo, mudó de dueño una sola vez en este tiempo. Felice Trocchi, posiblemente consciente de su valor arqueológico, si no artístico, decidió mantener en su poder la escultura bifronte que inexplicablemente el Príncipe de la Paz no había llevado consigo a Francia en 1832.

Tenemos que esperar hasta ya avanzado el siglo XIX para volver a dar con el paradero del herma, el cual aparece citado en los documentos de una transacción que no llegó a tener lugar, su venta al Museo Capitolino. En agosto de 1874, un familiar de aquel acreedor del Príncipe de la Paz, Rocco Trocchi, proponía al Municipio de Roma la compra de su escultura con el objeto de que fuera exhibida con las demás antigüedades del Museo Capitolino $^{51}$ y para apoyar su oferta presentaba una copia de un informe realizado por el arqueólogo G. B. de Rossi junto al epigrafista alemán G. Henzen en junio de ese año, relativa a la singularidad de la pieza. Ambos especialistas examinaron una vez más las letras que componían la inscripción y determinaron que por su forma y su ejecución en la superficie del mármol eran genuinas, datándolas en la época de los Flavios, o de los primeros Antoninos, periodo al que más se adecuaba el estilo de la escultura ${ }^{52}$. La Junta Municipal de Roma, a la vista de estos datos, se remitió a la Comisión de Arqueología, cuyo secretario era Rodolfo Lanciani, para que determinaran si la compra resultaba aconsejable. La Comisión reconocía en su sesión de 16 de noviembre de 1874 que el herma era de particular importancia y que sería favorable efectuar la operación; siguiendo este parecer, a comienzos de 1875 la Junta Municipal dio un voto positivo a que la propuesta de Trocchi se presentara ante el Consejo Comunal romano y así conseguir para el Museo Capitolino una talla de gran significación, la única con el verdadero rostro de Séneca. El Asesor Comunal, G. Marchetti, delegó en Rodolfo Lanciani para que consultara a Rocco Trocchi el precio por el que ofrecía el herma, pero la entrevista entre ambos no se concretó, porque éste prefirió negociar directamente con el secretario general de la Comisión de Arqueología. A mediados de febrero Trocchi retiraba su proposición y ponía fin a las conversaciones comenzadas, "por temor a que el Consejo Comunal rechazara su oferta", según declara Lanciani. No se explica bien este cambio de actitud, ya que el Consejo había dado el visto bueno

${ }^{51}$ Toda la documentación presentada en relación a este tema se halla en el ASC. Monumenti scavi antichità Musei, serie I, 1871/1920. Erma bicipite di Socrate e Seneca rinvenuta nella villa Mattei sull Celio. Sull'acquisto da parte del Museo Capitolino 1874,5 giu/1875, feb. 16. Busta 1, fasciculo 91.

${ }^{52}$ G. B. de Rossi menciona asimismo las sospechas de las que fue objeto el epígrafe del Séneca en el momento de su hallazgo, de las que no se libró hasta la publicación de Lorenzo Re. 


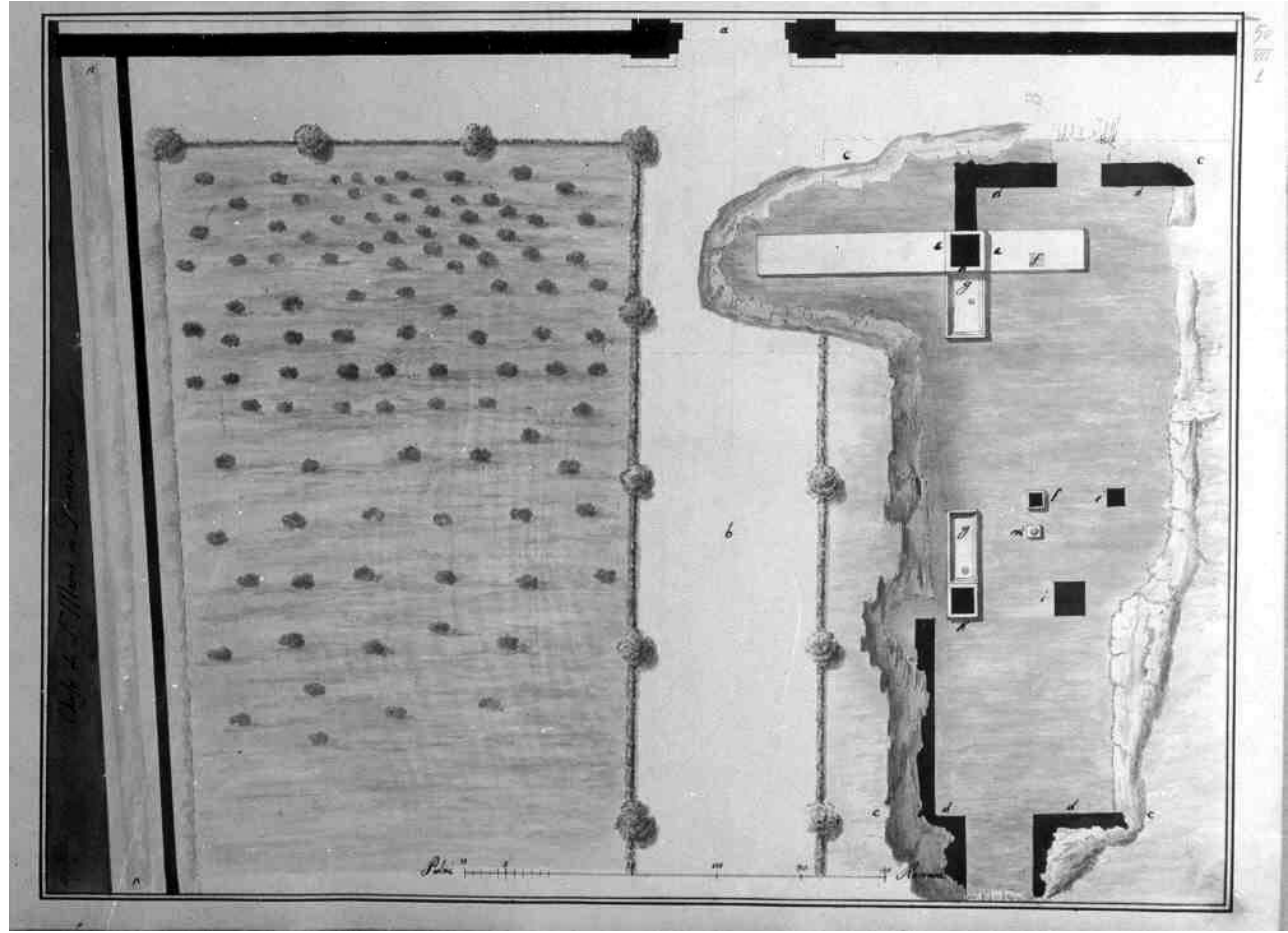

Figura 8. Piante che dimostrano i luoghi ove furono rinvenuti nella nella Villa Celimontana, già Mattei, i marmi dei Vigili... Planimetría. 1820. Roma. BIASA. R.XI.50.VII.1.

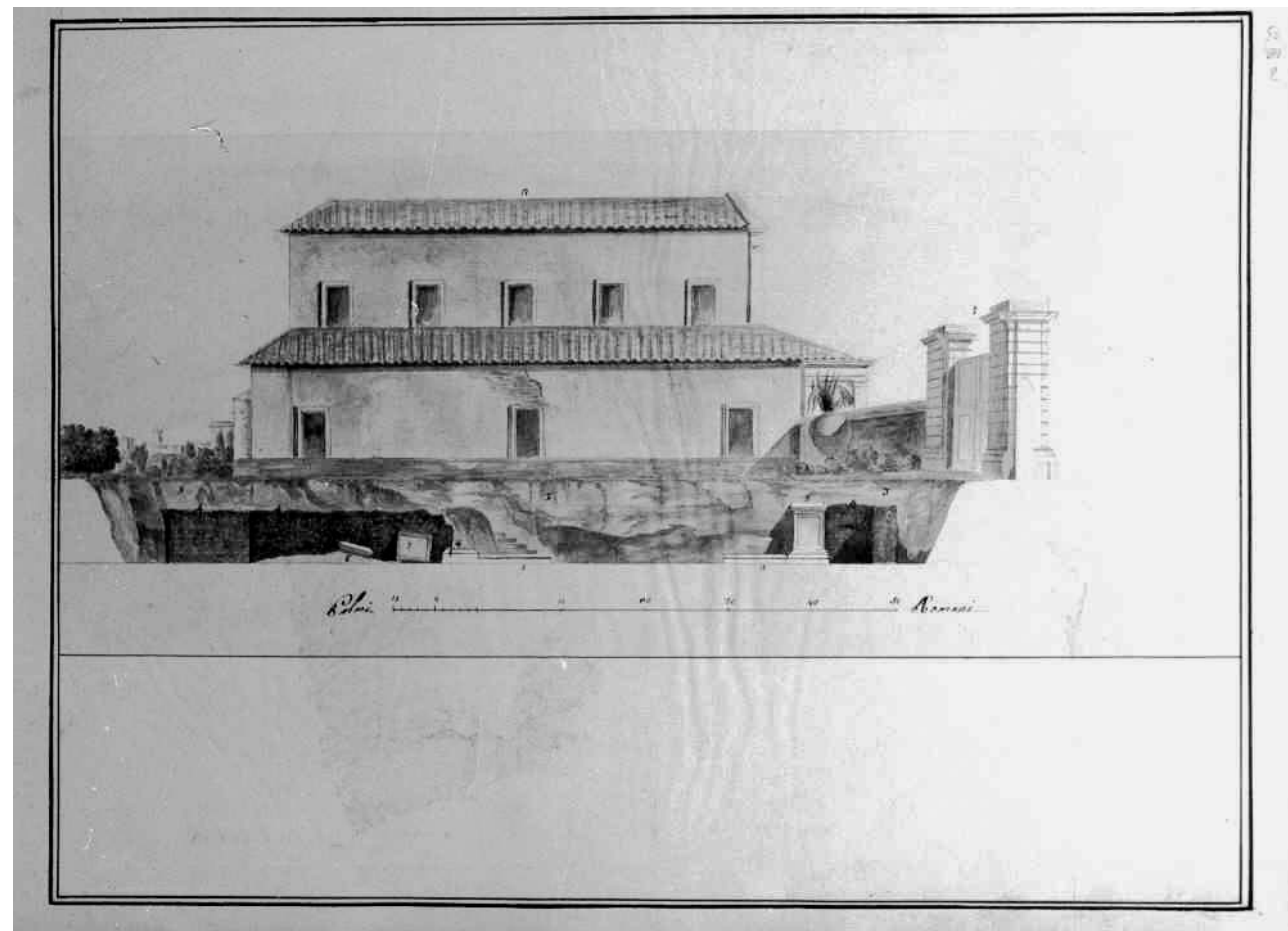

9. Piante che dimostrano i luoghi ove furono rinvenuti nella nella Villa Celimontana, già Mattei, i marmi dei Vigili... Sección longitudinal.1820. Roma. BIASA. R.XI.50.VII.2. 
a llegar a un acuerdo con el propietario del herma bicípite, pero se puede especular con la posibilidad de que el precio establecido por Trocchi fuese demasiado alto y el Consejo intentara rebajarlo. El herma figura actualmente en la colección del Museo de Berlín, con el número de inventario 391; fue adquirido en el mercado de antigüedades de Roma en $1878^{53}$, lugar en el que Trocchi efectuaría finalmente la venta de su escultura poco tiempo después del fallido intento de venta al museo italiano ${ }^{54}$. De la doble talla de Sócrates y Séneca por la que Godoy sintió tanto afición sólo queda en Roma un vaciado en yeso expuesto en el Museo della Civiltà Romana ${ }^{55}$.

\section{LAS EXCAVACIONES DE 1820: LAS BASAS DE LA COHORS V VIGILUM}

La participación de Celles en las excavaciones de 1820 , cuyo resultado fue el descubrimiento de dos basas de estatua dedicadas a Caracalla a comienzos del siglo III d.C. ${ }^{56}$, ha suscitado dudas en la bibliografía española e italiana, cuestión a la que se debe responder definitivamente de forma negativa. El problema estribaba en la atribución al pensionado de una serie de dibujos guardados en la Biblioteca del Instituto de Arqueología e Historia del Arte de Roma ${ }^{57}$ relativos a dichas excavaciones, lo que anticipaba su fecha al menos en cinco años, ya que Celles abandonó Italia en 1815. Lanciani, Colini y Juan Bassegoda Nonell adjudicaron equivocadamente al arquitecto catalán esos planos, aunque las publicaciones coetáneas no dan lugar a dudas sobre su cronología. De los dibujos, sólo la ilustración del mosaico restaurado por los hermanos Cocchi en 1814 sí pertenecía al pensionado de la Junta de Comercio, lo que fácilmente llevó a Lanciani al engaño de vincularlo con

${ }^{53}$ María José Muñoz López, "Iconografía de Séneca en Córdoba", en Miguel Rodríguez Pantoja (ed.), Séneca dos mil años después. Actas del Congreso Internacional Conmemorativo del Bimilenario de su Nacimiento, Córdoba, 1996, p. 796.

${ }^{54}$ La adquisición del herma por el Museo de Berlín aparece con dicha fecha en los catálogos Beschreibung der antiken Skulpturen mit usschluss der Pergamenischen Fundstücke, Berlín, 1891, pp. 158-159; Carl Blümel, Römische..., op. cit. n. 32, p. 44; AA. VV., Die Antikensammlung im Pergamonmuseum und in Charlottenburg, Berlín, 1992, pp. 215 y 216.

55 AA. VV., Museo della Civiltà Romana Catalogo, Roma, 1982, p. 573.

${ }^{56}$ CIL., VI, 1057 y 1058.

${ }^{57}$ Estos diseños están clasificados entre otros de la Villa Mattei con el título "Piante che dimostrano i luoghi ove furono rinvenuti nella Villa Celimontana, già Mattei, i marmi dei Vigili, ed ove di questi erano le Stazioni”. BIASA. Roma XI. 50.VII. 1-5. los demás, porque además desconocía la fecha en que Antonio Celles partió hacia España.

La autoría de las excavaciones de 1820 escapa a nuestro conocimiento. D. O. Kellermann, que fue quien analizó con mayor profundidad los pedestales en 1835, no participó directamente en ellas. Robert Sablayrolles menciona a Girolamo Amati (1768-1834), quien habría llamado la atención del arqueólogo alemán sobre el interés de estudiar ambas piezas ${ }^{58}$. Amati era arqueólogo y epigrafista, miembro de la Pontificia Accademia Romana di Archeologia y bibliotecario de la colección Vaticana, datos que respaldarían su intervención, la cual mantendremos como mera conjetura.

El abogado Carlo Fea da cuenta del hallazgo de los pedestales en el mes de enero de 1820 en un escrito que se editó en ese mismo año ${ }^{59}$. El punto en donde tuvieron lugar las operaciones arqueológicas, situado a la derecha de la iglesia de Santa María in Domnica, junto a la puerta de ingreso de ese sector de la villa, fue representado por Rodolfo Lanciani en su Forma Urbis gracias a la indicación recibida por los dibujos atribuidos a Celles ${ }^{60}$. Éstos consisten en una planimetría de la excavación, en la que se observa cómo los trabajos invadieron la vía que comunicaba el palacio con el mencionado ingreso, motivo que había llevado en el pasado a empezar algunas de las demás excavaciones (Fig. 8); su sección longitudinal, dejando al otro lado del camino la fachada sur de la Navicella (Fig. 9); la sección transversal, con el templo de San Stefano Rotondo más allá del muro que rodeaba la propiedad y la planta y detalle de una basa octogonal (Fig. 10) y el último es la copia de las dos basas de mármol inscritas, una de las cuales tenía su cornisa desprendida (Fig. 11). Las medidas del hueco excavado se señalan en palmos romanos, siendo de 15 palmos la profundidad a la que se encontraron las dos piezas, según relata Carlo Fea. Ambas permanecían apoyadas sobre un pavimento antiguo, "di coccio pesto a stagno", es decir, un suelo de grava, con una

\footnotetext{
${ }^{58}$ Robert Sablayrolles, Libertinus Miles. Les cohortes de vigiles, Roma, 1996, p. 259, n. 39.

${ }^{59}$ Carlo Fea, Frammenti di fasti consolari e trionfali ultimamente scoperti nel foro romano e altrove ora riuniti e presentati alla santità di N. S. Pio Papa settimo, Roma, 1820, pp. 81-83.

${ }^{60}$ Ver R. Lanciani, Forma Urbis..., op. cit. n. 17, f. 36. En su historia de las excavaciones de Roma puntualiza en dos ocasiones las de los dos pedestales, emplazándolas en 1820 "Iscrizioni rinvenute nella villa Mattei riguardanti la V coorte dei vigili" y 1821 "Scoperte entro la villa gia Mattei vicino al ingresso ed a destra della chiesa di S. Maria in Domnica". Íd., Storia degli scavi di Roma e notizie intorno le collezioni romane di antichità (1700-1878), Roma, 2000, vol. VI, p. 243.
} 


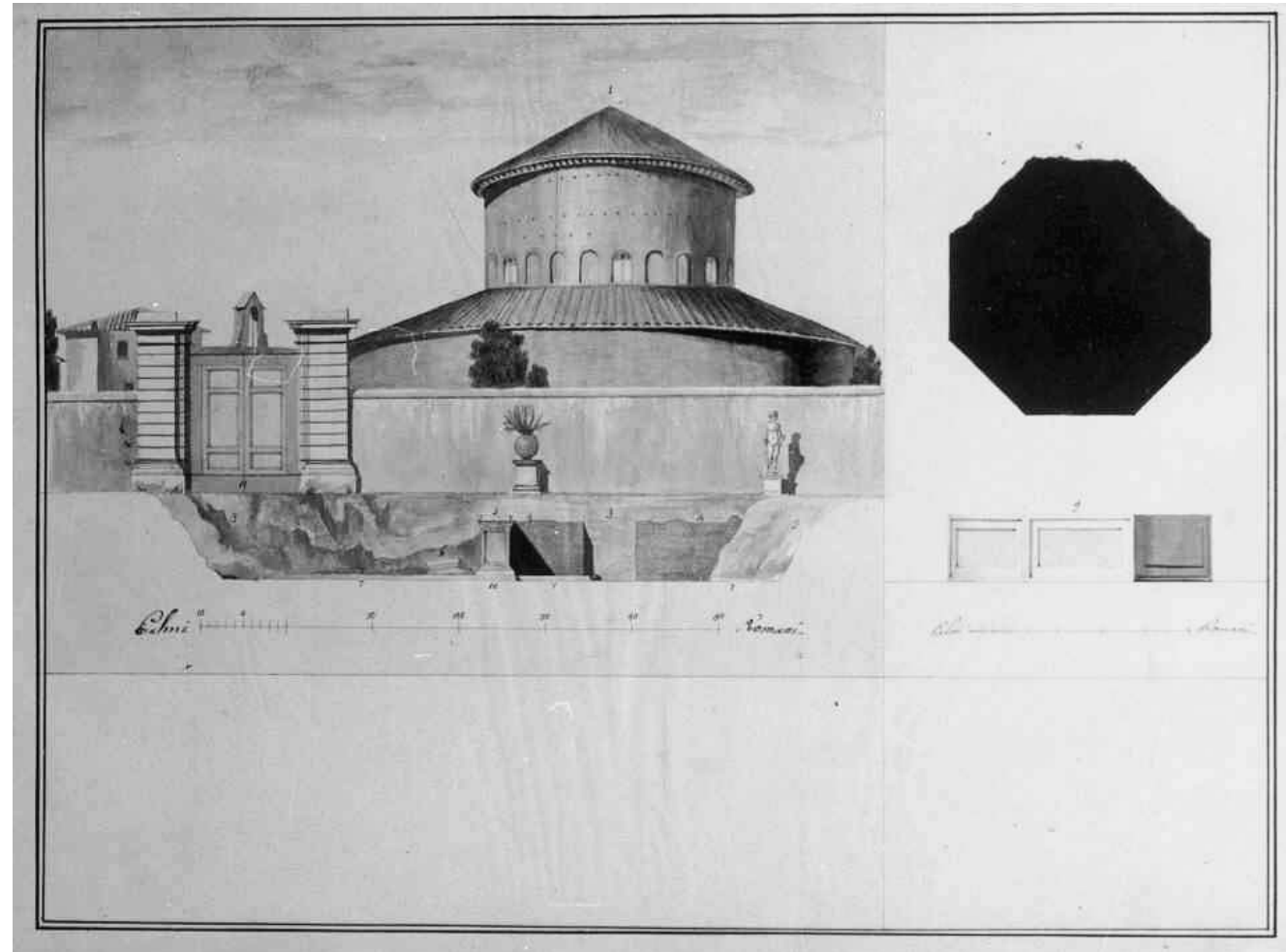

Figura 10. Piante che dimostrano i luoghi ove furono rinvenuti nella nella Villa Celimontana, già Mattei, i marmi dei Vigili... Sección transversal. 1820. Roma. BIASA. R.XI.50.VII.3.

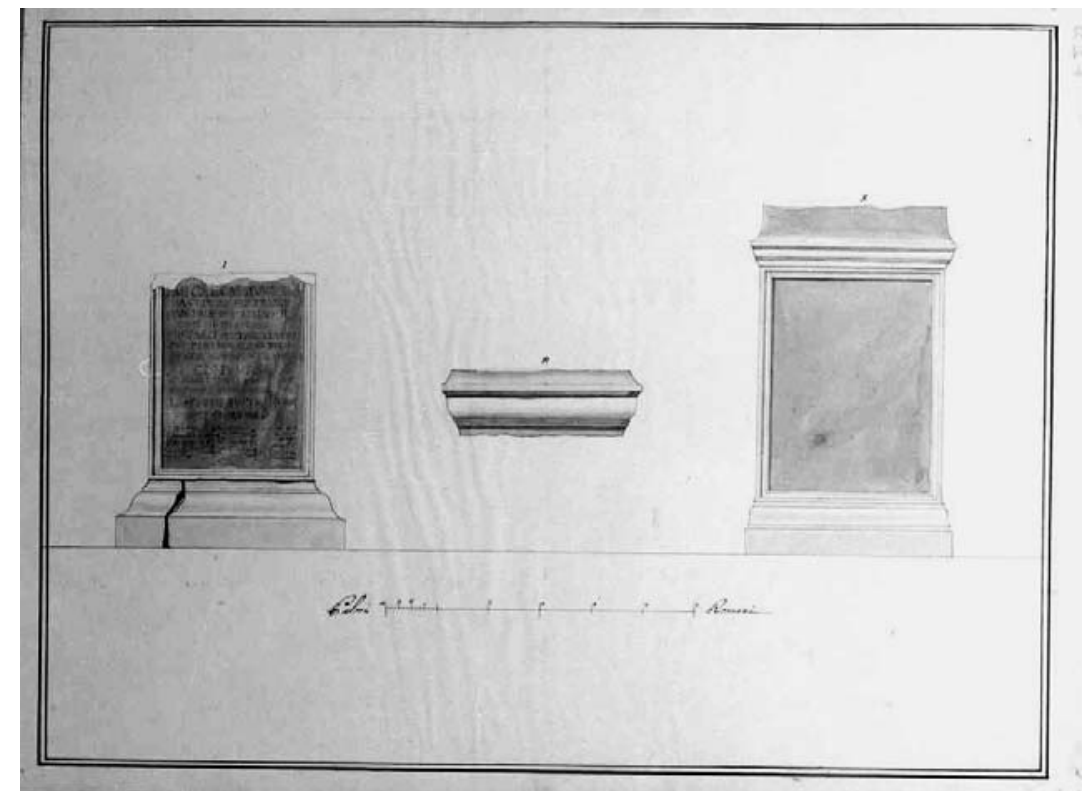

Figura 11. Piante che dimostrano i luoghi ove furono rinvenuti nella nella Villa Celimontana, già Mattei, $i$ marmi dei Vigili... Basas de la V Cohorte. 1820. Roma. BIASA. R.XI.50.VII.4. 
lastra de travertino a su lado y en ángulo recto cada una; dichas lastras tenían un agujero, que en opinión de Fea, y también de Kellermann, servían para introducir las insignias de la cohorte ${ }^{61}$. En cambio, Colini sugiere que se pueden parangonar con las que se ven delante de los templos destinadas a recoger los líquidos que se esparcían durante las ceremonias sacras ${ }^{62}$, mientras que Stefania Capponi y Barbara Mengozzi hallan poco convincente la explicación de los dos primeros, aduciendo que el cuerpo de vigiles no estaba dotado de signa ${ }^{63}$.

A través de los planos de excavación se puede conjeturar que estaban dispuestas en un recinto de considerable tamaño del cuartel de la $\mathrm{V}$ cohorte, o más probablemente en un patio, más acorde con su tipo de pavimentación, en el que se abrían tres ingresos, dos laterales y uno central, orientado hacia Santa María in Domnica, a cuyos extremos se asentaban las basas y los bloques de travertino. G. Mancini menciona que lo que se sacó a la luz en esta ocasión fueron varios ambientes con mosaicos y decoración parietal de estuco y al fresco, afirmación que no se confirma mediante los dibujos y que tal vez provenga de mezclar la información del conjunto de las excavaciones de Celles y Godoy ${ }^{64}$. R. Lanciani, por su lado, consideraba el lugar en el que aparecieron las basas un vestíbulo y, según una noticia transmitida por el mismo autor, Luigi Rossini aseguraba que en las excavaciones de 1820 se descubrió también la prisión del cuartel, come provano i ferri e catene ancora affissi alle pareti ${ }^{65}$. Uno de los pedestales tenía debajo una laja que se extendía hacia el vial de entrada y la Navicella, resto del pavimento de la estancia, por lo que sabemos que ésta se prolongaba por aquel lado del jardín Mattei. Entre las obras de renovación de la Plaza de la Navicella de 1931, un paso que se dio fue colocar un nuevo portal a la Villa Celimontana, por lo que casi en el mismo punto que se había excavado en 1820 , se pudieron ver seis pequeñas estancias alinea-

${ }^{61}$ Sitae erant decem vel quindecim palmos sub superficie terrae supra pavimentum arte factum, in quo immissae erant duae tabulae lapidis tiburtini, utraque foramine instructa, quae quidem insignibus cohors infigendis inserviisse videntur. Danus Olaus Kellermann, Vigilum romanorum latercula duo coelimontana, Roma, 1835, p. 3.

${ }^{62}$ A. M. Colini, Storia e topografia..., op. cit. n. 5, p.228.

${ }^{63}$ Stefania Capponi y Barbara Mengozzi, I vigiles dei Cesari. L'organizzazione antincendio nell'antica Roma, Roma, 1993, p. 195.

${ }^{64}$ Gioacchino Mancini, "I vigili dell'antica Roma", Roma, $\mathrm{n}^{\circ}$. 11, Roma, 1931, p. 543.

${ }^{65}$ R. Lanciani, Rovine e scavi di Roma Antica, Roma, 1985 ( $1^{\mathrm{a}}$ ed. Londres, 1897), p.298. das hacia dicho sitio con los muros de obra mixta de reticulado y latericio, con un corredor pavimentado en opus spicatum. Continuando por el muro de la villa en dirección sur, el alargamiento de la vía de la Navicella todavía deparó más novedades: se localizaron cinco grandes piezas de 3,40 de ancho por 7 metros de largo de media cuya posición era paralela a la del resto de las salas precedentes, pero con la entrada al lado opuesto, es decir, hacia la calle; su disposición a modo de tabernae dejaba un espacio intermedio entre dos de ellas, que indicaba el arranque de unas escaleras. No se sabe con seguridad si estos ambientes pertenecen al edificio que albergaba a la $\mathrm{V}$ cohorte, pero sí que no continuaban en ninguno de los dos sentidos del muro, porque las excavaciones de 1931 sólo se tropezaron en el lado sur con construcciones de una fase posterior ${ }^{66}$. Pudieran ser, siguiendo a Sablayrolles, una sucesión de negocios adheridos al cuartel de la cohorte, al que se podría acceder a través de las escaleras referidas.

La certeza de a qué edificación correspondían todos estos recintos, exceptuando los precedentes, la proporcionó el descubrimiento un siglo atrás de las basas tantas veces citadas ${ }^{67}$. Gracias a ellas se pudo enclavar el cuartel de la Cohors V Vigilum, cohorte de la que sólo se sabía que servía en la II región augustea (Caelimontium) ${ }^{68}$, de manera que fue la única conocida hasta que en 1858 G. B. de Rossi fijó la I, II y la IV ${ }^{69}$. Los dos pedestales estaban dedicados al hijo de Septimio Severo, M. Aurelio Antonino Pío -llamado usualmente Caracalla, y cuya estatua sustentarían,

${ }^{66}$ A. M. Colini, "I dintorni della Navicella nell'epoca antica", Capitolium, no. 4, 1931, pp. 158-161; S. Capponi y B. Mengozzi, I vigiles dei Cesari..., op. cit. n. 60, p. 96.

${ }^{67}$ Estos dos soportes de mármol fueron colocados en el interior del palacio del Príncipe de la Paz y Bassano; hacia 1870 se hallaban depositados bajo el pórtico del palacio y veinte años después se veían en el jardín, en el vial que conduce a la plaza del obelisco. A comienzos del siglo XX se trasladaron a la sala III del Antiquarium del Monte Celio (Antiquarium, Roma, 1929, p. 32). Hoy se ven en la Galería Lapidaria de los Museos Capitolinos, mientras que una copia muy deteriorada en cemento de cada una permanece en el jardín de la Villa Celimontana, al lado derecho del palacio, no muy alejadas del lugar en donde se encontraron.

${ }^{68}$ En realidad la V cohorte también actuaba en la I región (Porta Capena), aunque tenía su sede en el monte Celio. El resto de las cohortes se distribuían en las siguientes regiones: la $1^{\mathrm{a}}$ en la VII, la $2^{\mathrm{a}}$ en la V, la $3^{\mathrm{a}}$ en la VI, la $4^{\mathrm{a}}$ en la XII, la $6^{\mathrm{a}}$ en la VIII, y la $7^{\text {a }}$ en la XIV. A. Pellegrini, "La Settima coorte dei vigili, scavi di Roma", Bulletino dell'istituto di correspondenza archeologica, Roma, 1867, p. 8.

${ }^{69}$ G. B. de Rossi, "Le stazioni..., op. cit. n. 12, pp. 265297. 


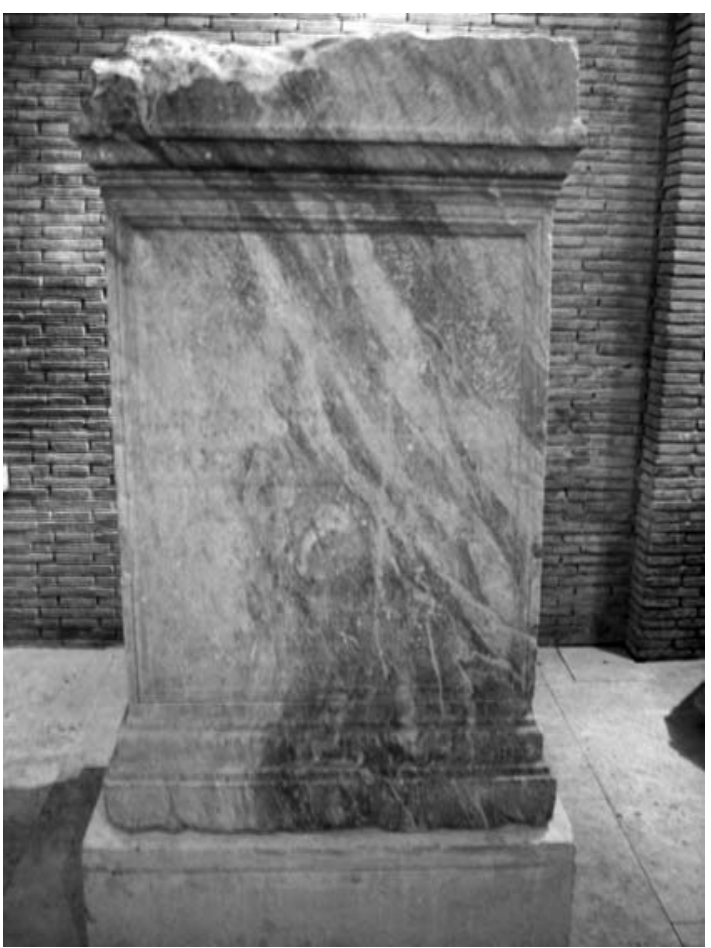

Figura 12. Basa del 205 d.C. Roma. Museos Capitolinos. Foto de Mariano Rodríguez Ceballos.

en el 205 y 210 d.C. ${ }^{70}$. Mientras que en aquélla la dedicatoria, que tendría que figurar sobre la cara delantera, por razones desconocidas no llegó a grabarse (Fig. 12), la de la segunda se encuentra perfectamente conservada (Fig. 13). Colini pensó que faltaba la inscripción porque estaba abrasada, en tanto que Kellermann supuso que el considerable número de errores cometidos por el grabador había provocado la interrupción del trabajo, aunque difícilmente eso explica por qué se mantuvo la basa inacabada en el recinto del cuartel. Las caras laterales y la trasera muestran en ambas el listado de los individuos componentes de la cohorte en el respectivo año, divididos

${ }^{70} \mathrm{Al}$ carecer de la dedicación al emperador la primera de las basas, la cronología del 205 es sólo una suposición: en dicho año la I y IV cohortes brindaron sendas dedicaciones a Caracalla (CIL. VI, 1056 y CIL. VI, 1055), al igual que la II cohorte en el 210 (CIL. VI, 1059); la coincidencia de estos años con la fecha de uno de los pedestales de la $\mathrm{V}$ cohorte y la existencia de otro sin poder datar ha hecho pensar en la posibilidad de que la más antigua se pueda ubicar en el 205, momento en el que Caracalla recibió el homenaje de diferentes cohortes de vigiles. R. Sablayrolles, Libertinus Miles..., op. cit. n. 55, p. 176 y 177, n. 5. En adelante, para facilitar su identificación, se aludirá a esta pieza unida a dicha datación.

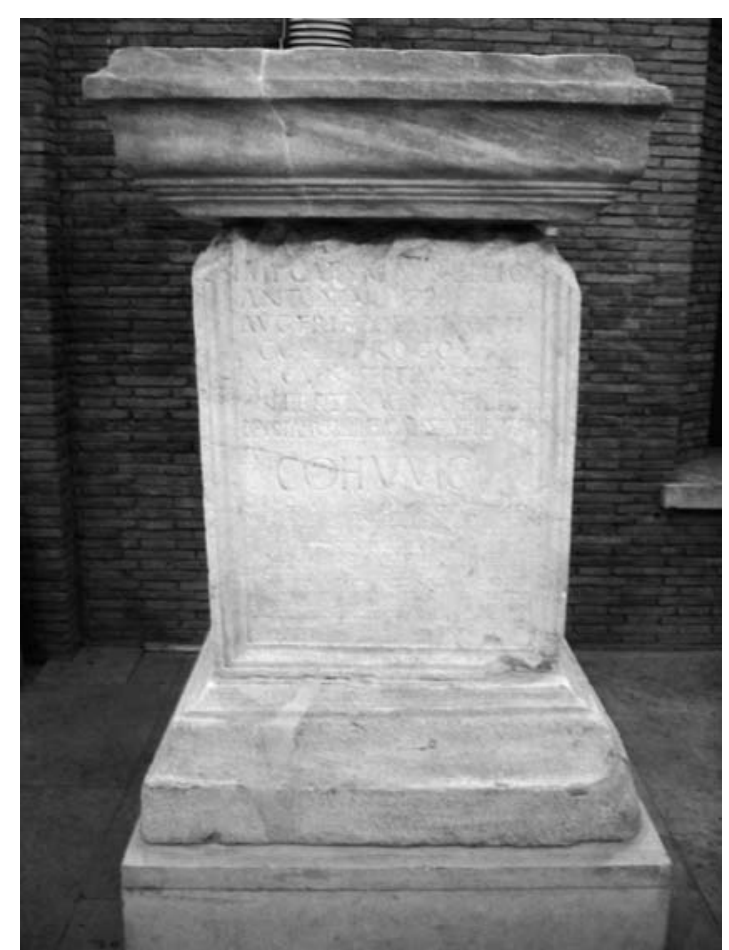

Figura 13. Basa con la dedicación a Caracalla del 210 d.C. Roma. Museos Capitolinos.

Foto de Mariano Rodríguez Ceballos.

por centurias. En general aportan valiosísima información sobre este cuerpo, su organización y jerarquías -sus inscripciones son el documento más completo, prácticamente el único, en que nos aparece descrita la organización de una cohorte de los bomberos y guardia urbana de Roma, al menos para una época determinada-, y junto a otra basa del 205 d.C. de la I cohorte, representan un $86 \%$ de los nombres conocidos del personal de las siete cohortes. Solamente la del 210 supera los 1.100 nombres escritos en tres de sus caras de los 2.027 presentes en los tres pedestales aludidos. Su valor aumenta si le añadimos que la historia de este cuerpo de vigiles no se conoce con excesiva prolijidad y la parquedad de datos sobre su estructuración original o la ubicación de algunas de sus stationes y excubitoria todavía son objeto de discusión ${ }^{71}$.

Las fuentes nos informan de la disponibilidad durante la República de contingentes de esclavos públi-

\footnotetext{
${ }^{71}$ Cada una de las siete cohortes tenía asignada la vigilancia de dos regiones adyacentes; en una se colocaba su cuartel, y en la otra un cuerpo de guardia más reducido, siempre en el perímetro de la Muralla Serviana, y cercanas a sus puertas.
} 
cos a cuya cabeza se hallaban los tresviri capitales o nocturni, encargados de extinguir los desastrosos incendios que tan habitualmente se producían y propagaban por las hacinadas construcciones de madera de la ciudad $^{72}$; a ellos se les sumaba la participación de compañías de siervos privados, puestos a disposición por sus amos de forma gratuita o esperando obtener alguna recompensa. Dentro de sus reformas administrativas Augusto instituyó el cuerpo de la Guardia en el 6 d.C., militarizándolo y ampliando sus funciones con el servicio de policía urbana, con una configuración que es la que básicamente encontramos en época severiana, como testimonian las basas descubiertas en 1820 en los terrenos de la Villa Celimontana.

Como hemos apuntado, ambas tenían inscritos los nombres y cargos de los componentes de la V cohorte en sus caras laterales y trasera, pero sólo la del año 210 presentaba en la delantera la dedicatoria al emperador Caracalla. También la disposición de los epígrafes difiere en uno y otro pedestal: mientras que el del 210 sigue un orden jerárquico, y el texto lo encabezan el praefectus vigilum y los oficiales superiores en cada centuria, seguidos por el conjunto de la milicia, en el primero prima el principio de la antigüedad, por lo que los principales pueden estar intercalados entre los soldados de la cohorte, ya que la presteza en promocionarse difería en cada caso ${ }^{73}$. Algunos datos a destacar son la identificación de un gran número de personajes que en el espacio de esos cinco años habían sido elevados de rango y la coincidencia entre los nominados a la cabeza de las centurias en ambos pedestales, puesto que en general, los más antiguos poseían la graduación mayor.

La información que nos aportan las basas afecta a un total de 1.043 hombres en la primera y 1.122 en la segunda, de los cuales aproximadamente un tercio son la misma persona, que se menciona en las dos listas ${ }^{74}$. Mientras que del cuerpo de esclavos escogidos para estas labores durante la República no sabemos su número u organización, la constitución de los vigiles no nos plantea ninguna duda: existían siete cohortes compuestas por unos 1.000 o 1.200 hombres cada una, que a su vez se dividían en siete centurias, a diferencia de las tropas del ejército que lo hacían en diez. La autoridad

72 Anna Maria Ramieri, I vigili del fuoco nella Roma Antica, Roma, 1990, p. 7. Entre las fuentes citadas se encuentran Pablo (Dig., I, 15,1) y Livio (XXXIV, 16).

${ }^{73}$ R. Sablayrolles, Libertinus Miles..., op. cit. n 55, p. 177; P. K. Baillie Reynolds, The vigiles of Imperial Rome, Oxford, 1926, pp. 71 y 72 .

${ }^{74}$ Estas son las cifras que se ofrecen en R. Lanciani Rovine e scavi..., op. cit. n. 62, p. 298; Baillie Reynolds, por otro lado, ante la ilegible lectura de algunos nombres se decanta por una cantidad de 925 y 958 en los respectivos basamentos. P. K. Baillie Reynolds, The vigiles..., op. cit. n. 70, p. 71, n. 2. superior la ostentaba el praefectus vigilum, normalmente procedente del orden ecuestre, a partir del cual descendía la cadena de mando en el subpraefectus y los tribuni vigilum, quienes se hallaban al frente de las cohortes, mientras que los centuriones se ocupaban de dirigir las centurias. Finalmente éstas se subdividían en una diversidad de oficiales, los principales, y en los milites o soldados comunes ${ }^{75}$.

A su vez, el punto en el que aparecieron las bases de las estatuas de Caracalla, unido a los vestigios restantes, nos habla de la estructura y el tamaño del cuartel de una Cohors Vigilum, de lo que verdaderamente sólo cabe especular, aunque se cuente con el ejemplo del de Ostia, del que se ha extrapolado a los de la ciudad de Roma. La ordenación de estas sedes de bomberos y guardias urbanos vendría a ser la misma que la de los mercados públicos o macella, con un amplio patio central porticado desde el que se distribuirían los demás espacios ${ }^{76}$, aproximadamente lo que se intuye en la planimetría de 1820: las imágenes del emperador enmarcarían la entrada del Augusteum, el recinto sagrado del culto imperial, tal vez sito en el extremo opuesto del patio al acceso principal. Si esto fuese así, el parecer de Carlo Fea sobre el uso de los agujeros de los bloques de travertino para encajar las insignias -si la cohorte las poseyera- tendría más lógica que el de Colini.

En este punto debemos retomar algunas de las excavaciones de Antonio Celles en el área comprendida entre la Navicella y el palacio de Manuel Godoy para interpretar los hallazgos que tuvieron lugar. Como se dijo en su momento, Lorenzo Re pensó que los dos pavimentos pertenecían a una villa cuyo titular se sentiría apasionado por las carreras de caballos, hecho que lo empujó a que dos de sus favoritos quedasen retratados en el piso de la residencia; igualmente Colini consideró que las estancias en las que estaban formaban parte de una vivienda, fundamentándose en que por su riqueza y su ubicación, era imposible relacionarlas con los ambientes del cuartel de la cohorte vecinos a la entrada de la Villa Mattei. Por el contrario, la bibliografía más reciente sobre las Cohortes Vigilum no descarta esta ligación y rebate los argumentos de Colini. No hay ninguna razón que excluya una decoración lujosa en los cuarteles de estas cohortes, como verifica el despojo de materiales constructivos de la Statio de la V desarrollado en los terrenos de la Villa Celimontana desde el siglo XVI: la gran cantidad de mármoles blancos y de colores que se destinaron a ornar la Sala Regia del Vaticano durante el pontificado de Pablo III, cuyo tamaño dificul-

75 Sobre la estructuración de las cohortes ver A. M. Ramieri, I vigili del fuoco..., op. cit. n. 69, p. 9 y ss.

${ }^{76}$ Acerca del cuartel de Ostia, o domus vigilum, S. Capponi y B. Mengozzi, I vigiles dei Cesari..., op. cit. n. 60, pp. 167-189; A. M. Ramieri, I vigili del fuoco..., op. cit. n. 69, pp. 27-29. 


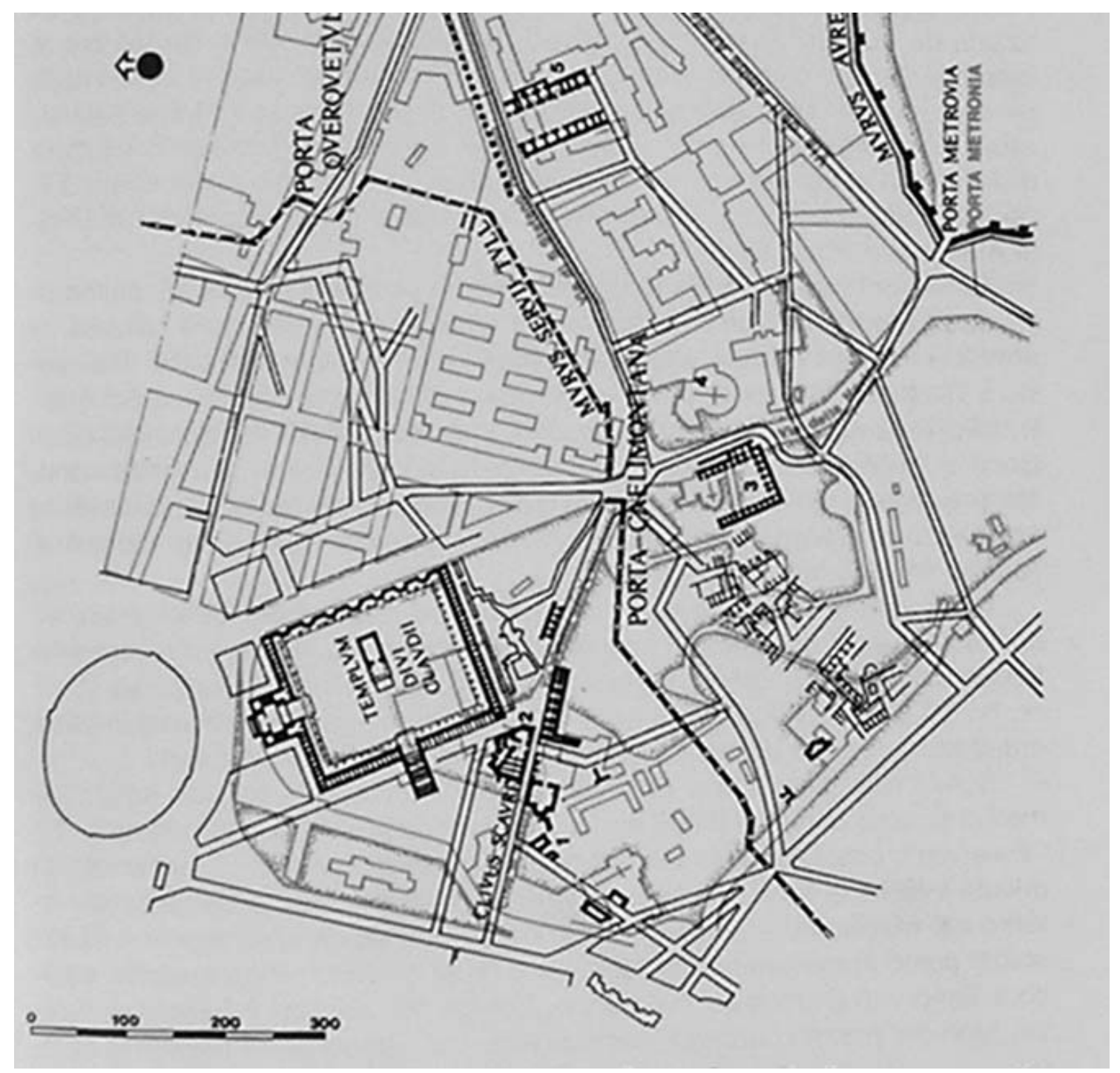

Figura 14. Localización en el Celio del cuartel de la V Cohorte (indicado con el n. o 3) según F. Coarelli (2001).

tó las labores de transporte hasta el punto de tener que derribar un muro de la villa (vinculados tradicionalmente a los restos de un templo por su suntuosidad); las columnas de portasanta retiradas de los jardines en 1732, o los materiales desenterrados en 1804 por el clérigo Nicolò Paccanari ${ }^{77}$, siendo propietaria la archiduquesa María Ana de Austria constituyen ejemplos de ello. La riqueza arquitectónica de los cuarteles se constata asimismo en el relato de los vestigios sacados a la

${ }^{77}$ En esta excavación se encontraron mármoles de menor calidad que en las anteriores. R. Lanciani, Storia degli scavi..., op. cit. n. 57 , p. 243. luz durante las obras de construcción del Palacio Savorelli; G. B. Mutti escribía en 1644: Si è scoperta una parte grandissima di una delle dette stazioni, con diverse stanze ed appartamenti ornati con colonne, pedestalli e statue, parte incrostati intorno con marmo, parte intonicate con la calce, con sedili o muricciuoli da sedere... ${ }^{78}$. El dato que permitió conocer la adscripción de esta edificación a la I cohorte fueron tres inscripciones, de las que al menos dos la mencionaban ${ }^{79}$. Incluso la

${ }^{78}$ Citado en G. B. de Rossi, "Le stazioni...”, op. cit. n. 12, p.269.

${ }^{79}$ Corresponden al CIL., VI, 233, 1092 y 1226. 
decoración arquitectónica del excubitorium o puesto de guardia de la VII cohorte en el actual barrio de Trastevere, fue definida como uno de los mejores ejemplos de ornamentación de época severiana por R. Lanciani ${ }^{80}$; el patio tenía un pavimento de mosaico blanco y negro representando animales marinos, motivo que se repetía en las pinturas de los muros de una de las estancias principales, al igual que en el corredor que conducía a ella.

A juicio de Colini, la distancia entre la zona de excavaciones de los pedestales de las estatuas y la de los pavimentos crea un espacio demasiado considerable como para tener en cuenta una conexión entre ellos; asimismo reconoce que los cuarteles eran "edifici piuttosto vasti perchè le coorti che ospitavano, erano forti di mille uomini ciascuna ed avevano un certo numero di cavalli e tutti gli attrezzi necessari alle loro speciali funzioni. Dobiamo quindi pensare che largo spazio della villa Celimontana fosse occupato dalle fabbriche di quella ivi esistente" ${ }^{81}$. Por ello, debemos contemplar que no sería tan desacertado vincular las estancias excavadas en 1814, a medio camino entre Santa María in Domnica y el palacio de Godoy, con aquéllas que ocupaban el lugar del ingreso a la villa y su muro, aunque resulta difícil determinar cuál sería el espacio completo ocupado por el castro a tenor de estos datos, si fuese cierto que se expandiese hasta allí ${ }^{82}$. Examinado el terreno in situ, la distancia entre la puerta orientada hacia San Stefano Rotondo y la parte posterior de la tribuna de dicha iglesia es escasa ${ }^{83}$. Por consiguiente, si mantenemos esta especulación, la delimitación del cuartel de la V cohorte viene dada en los siguientes términos: el lado este lo demarcan las piezas de obra mixta que se asomaban a la actual Vía della Navicella, que antiguamente comunicaba la Porta Caelimontana con la Porta Metronia, con las tabernae adosadas al cuartel a la manera de la Statio de Ostia. Colini establece este lado

${ }^{80}$ R. Lanciani, Rovine e scavi..., op. cit. n. 62, p. 470.

${ }^{81}$ A. M. Colini, "I dintorni della Navicella...", op. cit. n. 63, p. 161 .

${ }^{82}$ Nibby sitúa el cuartel de la cohorte en su guía de Roma entre el palacio del Príncipe de la Paz y la Navicella; el error lo debemos achacar a que confunde las excavaciones de 1814 con las de 1820, enclavando las basas en el punto en el que se recuperaron los dos pavimentos. A. Nibby, Itinerario di Roma..., op. cit. n. 24 , p. 89.

${ }^{83}$ R. Sablayrolles se muestra convencido de esta hipótesis, y aporta algunas medidas: "si on considère en effet les deux pièces à mosaïque comme la limite occidentale du bâtiment et l'ensemble de la via della Navicella comme la limite orientale, la caserne formerait un quadrilàtere dont le petit côté mesurait 55 à 60 mètres de long, ce qui est tout à fait conforme à la moyenne de ce que pouvait être les dimensions d'une caserme de vigiles". R. Sablayrolles, Libertinus Miles..., op. cit. n. 55, p. 260. como el frontal, pero resulta dudoso: las escaleras emplazadas entre dos de los comercios daban entrada desde la calle a los pisos del edificio podrían sugerir del mismo modo un ingreso secundario. La posición del lado oeste, lo hemos señalado, resultaría interesante relacionarlo con los pavimentos de mosaico y opus sectile encontrados por Celles en 1814. Al norte, el castro ocuparía una parte de la iglesia de Santa María in Domnica, hecho que confirma a grandes rasgos la arqueología, que revela que bajo ella no se esconde ningún edificio de tipo basilical, por lo que presumiblemente se adaptaría a los ambientes del cuartel existentes sin modificarlos ${ }^{84}$, y al sur el límite lo designaría el final de las construcciones del ala este o el propio desnivel de la colina celimontana (Fig. 14). El dibujo de la planimetría de 1820 parece enseñar que los pedestales se hallaban colocados en un patio, eje central de todo el cuartel. Su alineación sí presenta dificultades: si fuese de norte a sur, la sala en cuya entrada se erguían las estatuas de Caracalla la relacionaríamos con el Augusteum, acorde con el modelo de Ostia, encontrándose la fachada principal en el extremo meridional; esta disposición descartaría prácticamente que las estancias pavimentadas del oeste formasen parte del cuartel apostado en el Celio. Por el contrario, una orientación este-oeste (siempre fijándonos en el castro de Ostia) convertiría la fachada asomada a San Stefano Rotondo en la frontal, y a los ambientes pavimentados cercanos al ábside de la Navicella en dos posibles estancias del cuartel. Ante la imposibilidad de penetrar más allá en esta cuestión por la falta de otros datos, dejamos planteada la atractiva adscripción de los pavimentos a esta construcción antigua aún muy desconocida, pero apuntando que un estudio más profundo del tipo de pavimentos musivos de estos cuarteles, en el cual no nos hemos embarcado, podría aclarar todos estos interrogantes. Si a consecuencia de dicho análisis se demostrase la imposibilidad de que un mosaico de esas características pudiera adornar esta clase de establecimientos, decorados habitualmente con pavimentos de teselas blancas y negras, y apoyándonos además en la temática del excavado por Celles, sería a nuestro entender más correcta la atribución decimonónica a una villa de las que tanto abundaban en el Celio desde el siglo III d.C.

Respecto a la cronología del edificio, poseemos dos inscripciones de la V cohorte del 111 y el 113 d.C. ${ }^{85}$ relativas a la construcción de dos aediculae dedicados al Genio de la centuria, el primero de los cuáles hubo de ser restaurado en el 156 porque era ya "vetustate corruptae", que demuestran la existencia en el Celio

\footnotetext{
${ }^{84}$ Carlo Pietrangeli, Guide Rionaldi..., op. cit. n. 47, p. 19.

${ }^{85}$ CIL., VI, 221 y 222.
} 
del cuartel en ese momento, si bien nada sabemos del periodo anterior ${ }^{86}$. Las basas del 205 y 210 d.C. continúan hablándonos de la vida del cuartel bajo el reinado de los Severos, igualmente que los pavimentos y el herma rescatados por Godoy para adornar su palacio, si se adscribiesen a aquella edificación. Un término ad quem lo constituye la moneda de Felipe el Árabe recuperada en el lugar de excavación de la escultura bicípite, un ambiente común al del suelo de mosaico, que evidencia el uso de éste al menos hasta la mitad del siglo III d.C.

Manuel Godoy, Príncipe de la Paz, fue un continuador de la tradición anticuaria cuya mira apuntaba a la obtención de objetos bellos que decoraran los pala- cios de las casas nobiliarias y aunque en este sentido no tuvo la fortuna de hacerse con obras de gran espectacularidad, sí cumplían a la perfección con esos fines estéticos. $\mathrm{Su}$ valor arqueológico e histórico, bien entendido por él y del que sacó el máximo provecho social, sí era sin embargo relevante: el herma bicípite de Sócrates y Séneca constituye la única imagen existente del filósofo cordobés que instruyó a Nerón y las basas de la $\mathrm{V}$ cohorte indicaron por primera vez el emplazamiento seguro de uno de estos cuerpos de antiguos bomberos.

Recibido el 26/09/2005. Aceptado el 13/06/2006.

${ }^{86}$ Sobre estos aediculae véase A. M. Colini, Storia e topografia..., op. cit. n. 5, p.230; P. K. Baillie Reynolds, The vigiles..., op. cit. n. 70, pp. 43 y 44. A la vista de las técnicas constructivas empleadas, Coarelli le otorga una cronología de época trajana. F. Coarelli, Guida di Roma, Roma, 2001, p. 270. A tenor de que en época republicana se asentaran los recintos de los grupos de esclavos públicos que hacían las veces de bomberos próximos a las puertas de las murallas, cabe la posibilidad de que desde el reinado de Augusto tuviera la V cohorte su sede en el área de la Villa Mattei, reedificada con posterioridad por Trajano poco antes de la dedicación de los dos aediculae apuntados. S. Capponi y B. Mengozzi, I vigiles dei Cesari..., op. cit. n. 60, p. 96. 
